\title{
Mosaic Architecture of the Somatic Sensory-Recipient Sector of the Cat's Striatum
}

\author{
Rafael Malach ${ }^{1}$ and Ann M. Graybiel \\ Department of Psychology and Brain Science and The Whitaker College, Massachusetts Institute of Technology, \\ Cambridge, Massachusetts 02139
}

\begin{abstract}
The striatum is known to have a compartmental organization in which histochemically defined zones called striosomes form branched 3-dimensional labyrinths embedded within the surrounding matrix. We explored how fiber projections from cortical somatic sensory areas representing cutaneous and deepreceptor inputs are organized in relation to this striatal architecture. Areas SI and 3a were mapped electrophysiologically, and distinguishable anterograde tracers (wheat germ agglutinin-HRP and ${ }^{35} \mathrm{~S}$-methionine) were injected into physiologically identified loci.
\end{abstract}

Primary somatic sensory corticostriatal projections were confined to a small, well-defined sector in the dorsolateral corner of the ipsilateral striatum. The somatic sensory afferents were arranged according to a coherent global body map in which rostral body parts were represented more laterally than caudal body parts. Single cortical loci innervated branched and clustered striatal zones that were reminiscent of the striosomes in their range of sizes and shapes yet lay strictly within the extrastriosomal matrix. In contrast to the global orderliness of the striatal body map, there were clear examples of locally complex patterns in which functionally distinct inputs interdigitated with each other. These patterns were often, but not always, produced when corticostriatal afferents carrying different submodality types were labeled.

These findings demonstrate the existence of striosome-like striatal compartments within the seemingly uniform extrastriosomal matrix. The principle of mosaic organization thus holds throughout the tissue of the somatic sensory striatum. The striatal architecture delineated here could provide the anatomical substrate for computations requiring cross-modality comparisons within the framework of an overall somatotopy. If a similar multicompartmental architecture also characterices other striatal regions, as seems likely, it may set general constraints on the nature of associative processing within the striatum as a whole.

Many afferents of the basal ganglia, including the dopaminecontaining fibers from the midbrain, project to the striatum. The striatum in turn provides the main input to the pallidum and substantia nigra, the 2 largest output stations of the basal

\footnotetext{
Received Nov. 25, 1985; revised May 14, 1986; accepted May 15, 1986.

We wish to thank Ms. Dianne Sahagian and Mrs. Lisa Metzger Dunning for their help with the histology; Mr. Henry Hall, who was responsible for the photography; and Drs. R. Ho, R. Elde, and E. Benoit, who donated the antisera used. This work was supported by NIH EYO2866, The McKnight Foundation, The Seaver Institute, and a Bantrell Fellowship (R.M.)

Correspondence should be addressed to Ann M. Graybiel, Ph.D., Department of Brain and Cognitive Sciences and The Whitaker College, Room E25-618, Mas sachusetts Institute of Tcchnology, Cambridge, MA 02139.

Present address: The Weizmann Institute of Science, Center for Neurosciences and Behavioral Research, Rehovot, Israel.

Copyright (C) 1986 Society for Neuroscience $0270-6474 / 86 / 123436-23 \$ 02.00 / 0$
}

ganglia. The advantage gained by having the striatum interposed between the afferent and efferent sides of this extrapyramidal circuitry is not yet clear. Experimental work in the past 10 years, however, has provided an initial clue. Fiber systems projecting to the striatum and the cells of origin of striatal efferent projections are organized in relation to a compartmental plan of subdivision governing the distribution of nearly every neurotransmitter-related compound so far identified in the striatum. This neurochemical compartmentalization was first studied in detail with acetylcholinesterase (AChE) histochemistry (Graybiel and Ragsdale, 1978b, 1979). Zones of low AChE activity, about $0.2-$ $0.6 \mathrm{~mm}$ wide and of variable shape, appear in cross sections throughout the striatum, and, on serial-section reconstruction, the AChE-poor zones turn out to be parts of branched 3-dimensional labyrinths. These zones were given the name striosomes ("striatal bodies") to distinguish them from the extrastriosomal tissue or matrix in which they lay embedded (Graybiel and Ragsdale, 1978a).

The striosomes are now known to correspond to the opioid "receptor patches" first described by Pert et al. (1976) and to the regions of the striatum innervated during development by the "dopamine island" fibers (Olson et al., 1972; Tennyson et al., 1972; see Graybiel, 1984a; Herkenham and Pert, 1981). The striosomes are also set off from surrounding striatal tissue by having differentially high or low concentrations of several of the neuropeptides localized to the striatum by immunohistochemistry (Gerfen, 1984, 1985; Graybiel and Chesselet, 1984; Graybiel et al., 1981) and of certain nonopioid ligand binding sites detected by autoradiography (Goedert et al., 1984; Nastuk and Graybiel, 1985). All major classes of striatal afferents appear either to innervate these striosomes or to avoid them, depending on their sites of origin (Donoghue and Herkenham, 1983; Gerfen, 1984, 1985; Graybiel, 1984b; Graybiel and Ragsdale, 1979, 1983; Herkenham and Pert, 1981; Ragsdale and Graybiel, 1981, 1984). The efferent connections of striosomes and the extrastriosomal matrix are also distinct (Fishell and van der Kooy, 1984; Gerfen, 1984, 1985; Graybiel et al., 1979; Jimenez-Castellanos and Graybiel, 1985). The general view emerging from these findings is that transstriatal processing permits neurochemically specialized channels to be established in the basal ganglia.

Despite such rapidly accumulating anatomical and histochemical evidence for striatal compartmentalization, our understanding of how it might relate to the computations performed within the striatum is still meager. There have been several recent attempts to identify functional modularity in the striatum, however, and the initial results of such studies fit with the concept of compartmental ordering suggested by the anatomy. A patchy distribution of enhanced glucose utilization has been found with the 2-deoxyglucose method under certain conditions of cortical or pharmacological stimulation (Divac, 1983; McCulloch ct al., 1983). Electrophysiological studies have dem- 


\begin{tabular}{|c|c|c|c|c|}
\hline Case & WGA-HRP & ${ }^{35}$ S-Methionine & Histochemistry & Figure nos. \\
\hline CS-1 & Cut. trunk (1.3) & - & $\mathrm{AChE}$ & \\
\hline CS-4 & Cut. digit $5(1.75)$ & Cut. anterior trunk (1.5) & AChE & \\
\hline CS-5 & Deep forearm $(2.8)$ & Cut. forearm (2.4) & AChE & $3,7,8,10,12$ \\
\hline CS-7 & Deep trunk $+(2)^{a}$ & Cut. trunk (1.8) & & 2 \\
\hline CS- 8 & Cut. forearm (2.8) & Cut. shoulder (2.4) & & 2 \\
\hline CS-9 & Cut. ulnar forearm (2.6) & Cut. radial forearm $(2.0)$ & & \\
\hline $\mathrm{CS}-10$ & Cut. digit 4 (1.7) & Cut. hindpaw (1.4) & & $5,6,12$ \\
\hline $\mathrm{CS}-12$ & Cut. forearm (1.8) & Deep forearm (1.6) & & \\
\hline CS-14 & $\begin{array}{l}\text { Cut. hindpaw-neck } \\
\text { (8 i.s., } 1.5-2.5 \mathrm{~mm} \text { apart })\end{array}$ & $\begin{array}{l}\text { Deep hindpaw-forearm } \\
(5 \text { i.s., } 1.5 \mathrm{~mm} \text { apart, cont. })^{b}\end{array}$ & $\mathrm{AChE}$ & $7,9,10,12$ \\
\hline CS- 15 & $\begin{array}{l}\text { Deep cut. maps }+(30 \text { i.s., } 2 \mathrm{~mm} \\
\text { apart, mixed tracers })\end{array}$ & & & \\
\hline CS-16 & $\begin{array}{l}\text { Deep forepaw-shoulder } \\
\text { (4 i.s., } 0.5 \mathrm{~mm} \text { apart })\end{array}$ & $\begin{array}{l}\text { Cut. forearm-arm (continuous) } \\
\text { (4 i.s., } 0.7-0.5 \mathrm{~mm} \text { apart) }\end{array}$ & & \\
\hline CS- 17 & $\begin{array}{l}\text { Deep forearm-arm } \\
\text { (3 i.s., } 0.7-1.1 \mathrm{~mm} \text { apart })\end{array}$ & $\begin{array}{l}\text { Cut. forepaw-arm (continuous) } \\
\text { (3 i.s., } 0.6 \mathrm{~mm} \text { apart) }\end{array}$ & & \\
\hline \multicolumn{5}{|l|}{ CS-18 (both hemispheres) } \\
\hline Right & - & $\begin{array}{l}\text { Deep cut. shoulder-forepaw } \\
4 \text { i.s., } 1 \mathrm{~mm} \text { apart (continuous) }\end{array}$ & $\begin{array}{l}\text { AChE, BuChE, NADPHd } \\
\text { SOM, ENK, SP }\end{array}$ & 4 \\
\hline Left & - & Same as right hemisphere & & \\
\hline CS-19, area SIII & Vibrissae & Cut. lip-vibrissae (1.3) & SP & 2,12 \\
\hline CS-20 (both hemispheres) & & & & 2 \\
\hline Right & Cut. digit 5 (1.8) & Cut. trunk (1.7) (20R) & & 6 \\
\hline Left & Cut. elbow (1.8) & Cut. forepaw (1.4) (20L) & & 6,12 \\
\hline CS-21 & $\begin{array}{l}\text { Cut. digit } 4 \text {-lip } \\
16 \text { i.s., } 1 \mathrm{~mm} \text { apart }\end{array}$ & $\begin{array}{l}\text { Cut. digit 4-lip } \\
\text { (16 i.s., } 1 \mathrm{~mm} \text { apart, continuous) }\end{array}$ & SP & $1,4,11$ \\
\hline \multicolumn{5}{|c|}{ CS-22 (both hemispheres) } \\
\hline Right & - & Cut. forearm (2.2) & & 3 \\
\hline Left & - & $\begin{array}{l}\text { Cut. digit } 3 \text { (1.8); PHA-L digit } 3 \\
(0.9)\end{array}$ & & \\
\hline CT-2 & Cut. digit 4-5 (2.1) & Cut. digit $5(2.5)$ & & 6 \\
\hline
\end{tabular}

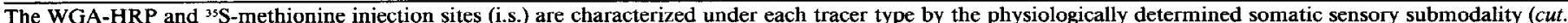

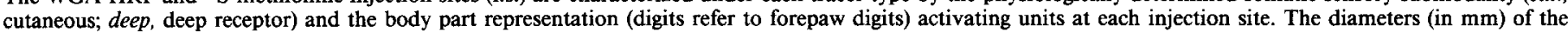

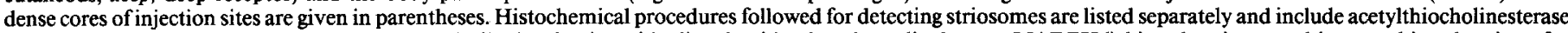

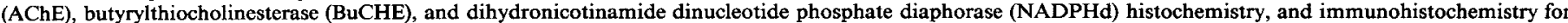

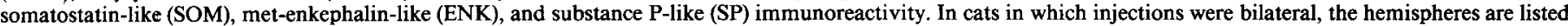
separately by side. Figures illustrating findings for individual cases are noted at right.

anjection site (i.s.) spread to the underlying dorsal bank of the cruciate sulcus.

${ }^{b}$ Stereotactically guided injection.

onstrated a distinct clustering of units with responses related to somatic sensory and motor properties (Alexander, 1984; Crutcher and DeLong, 1983; Liles and Updyke, 1985). Save for a single bricf rcport on glucose utilization (McCulloch ct al., 1983), none of these experiments has included a correlation between the functionally defined striatal regions and the striosomal compartments as identified histochemically.

In the study reported here, and briefly in Malach and Graybiel (1984), we adopted an indirect approach to evaluating such possible structure-function correlations. We explored, in relation to the striosomal system, the intrastriatal distribution of functionally identified corticostriatal afferents from the primary somatic sensory cortex. We chose the somatic sensory system because it is well represented in the striatum, and the projections of the feline primary somatic sensory (SI) cortex in particular because the SI region in the cat has a highly ordered somatotopic map that is represented on convexity cortex and that has been analyzed extensively (Dykes et al., 1980; Felleman et al., 1983; McKenna et al., 1981; Mountcastle, 1957; Sretavan and Dykes, 1983). We reasoned that by understanding the spatial transfor- mations of this map as it is projected onto the striatum and by learning how it relates to the histochemically defined striosomes, we might gain insights into striatal function and the significance of striatal compartmentalization.

\section{Materials and Methods}

The findings are based on data from 21 hemispheres of 18 adult cats in which pressure injections of either $10 \%$ wheat germ conjugated horseradish peroxidase (WGA-HRP) or $200 \mu \mathrm{Ci} / \mu \mathrm{l}{ }^{35} \mathrm{~S}$-methionine were placed at physiologically identified sites within the primary somatic sensory cortex. In 1 cat, the lectin PHA-L was delivered electrophoretically into the SI cortex. Table 1 summarizes the injection protocols for all experiments. In 5 cats, a single tracer (WGA-HRP or ${ }^{35} \mathrm{~S}$-methionine) was injected at 1 or more sites. In 5 other animals, the 2 tracers were injected separately at different sites within the cutaneous (SI) representation of the somatosensory cortex. In a third group of 7 cats, topographically comparable sites within cutaneous (SI), deep receptor (area 3a), or "SIII" (area 5) representations were injected with the 2 respective tracers. We studied the distributions of tracer labeling in the striatum resulting from these injections, including the relative locations, in sets of scrial sections, of the distinguishable tracers in the cases of double injection. In many 

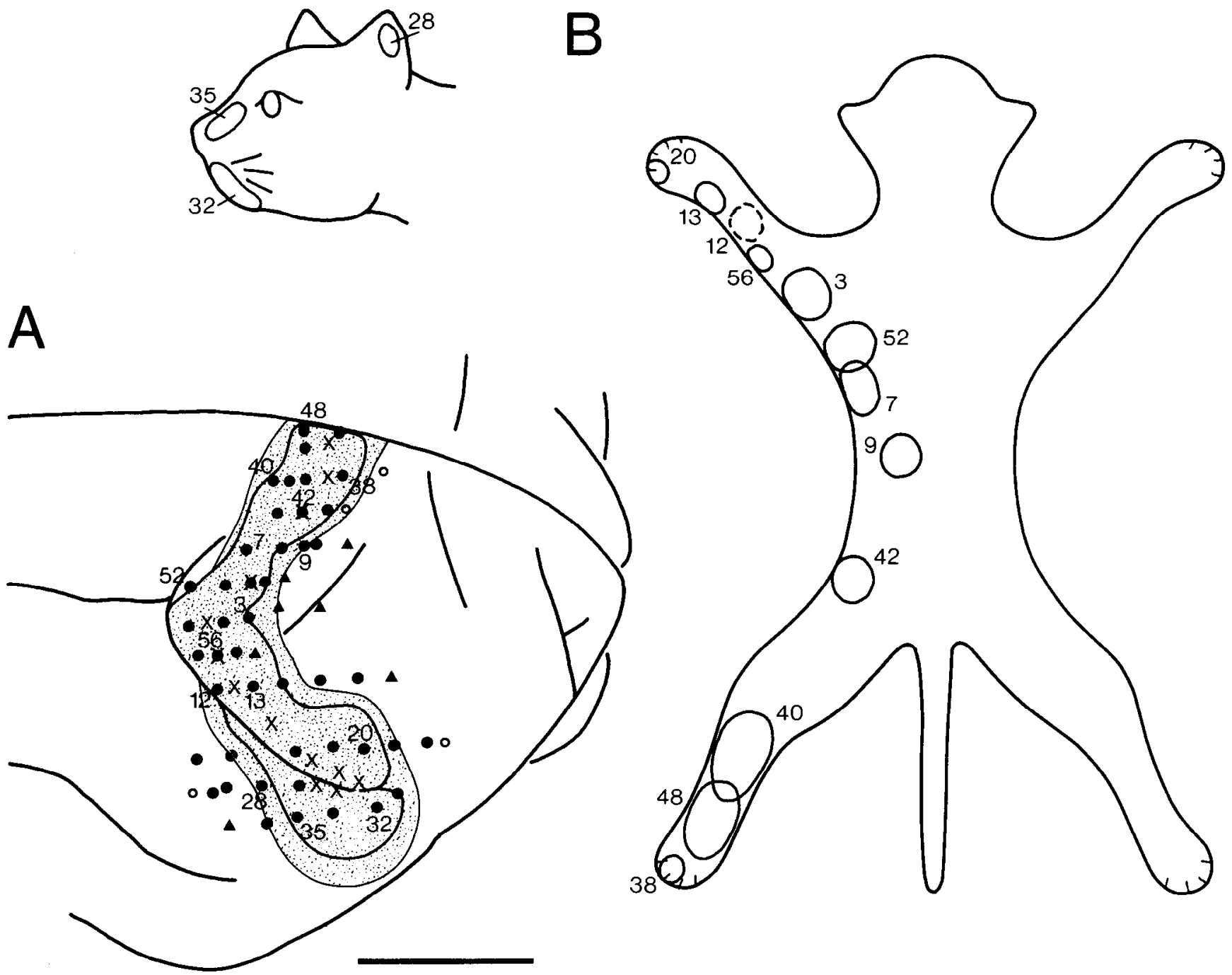

Figure 1. Composite cutaneous body map in area SI in case CS-21, derived from multiunit recordings. A, Dorsolateral view of the anterior part of the right hemisphere. Filled circles show location of recording sites at which cutaneous responses were found. Filled triangles indicate recording sites at which deep-receptor responses were encountered. Numbers mark recording sites for which receptive field locations are shown in $B$. Unresponsive sites are indicated by open circles. Injection pipette entrance points are shown at $x$ 's. Two additional injections were made deep in the lateral and medial banks of the coronal sulcus and are not shown. Scale bar, $5 \mathrm{~mm}$. B. Somatic sensory receptive fields of selected recording sites in case CS-21 shown on schematic figurine drawings (body shown in dorsal view). Numbered outlines indicate the body region from which a clear and consistent response to gentle cutaneous stimulation could be elicited. Interrupted outline at site 12 indicates receptive field on the ventral body surface. The numbers indicate the sequential recording sites at which these responses were found (cf. $A$ ).

cases, the distribution of the tracer labeling was also analyzed in relation to the locations of striosomes identified by the patterns of AChE activity or substance $\mathrm{P}(\mathrm{SP})$-like immunoreactivity present in adjacent sections.

\section{Electrophysiological recording and tracer injections}

The cats were anesthetized with a mixture of $13 \mathrm{mg} / \mathrm{kg}$ ketamine hydrochloride (Ketaject) and $0.6 \mathrm{mg} / \mathrm{kg}$ xyalazine (Rompun). This mixture was given in 3-4 similar dosages, as needed, during the experiment, and these were followed by additional dosages of ketamine. All animals were also treated preoperatively with $0.2 \mathrm{mg}$ atropine, $0.2-0.4 \mathrm{mg}$ dexamethasone (Azium), and 15,000 units of penicillin (Bicillin). The pericruciate cortex as far caudal as the ansate sulcus was exposed, photographed, and then covered with high-viscosity silicon fluid. Neuronal activity was recorded from small clusters of neurons with tungsten-inglass microelectrodes (Levick, 1972). The multiunit electrical signals were amplified, displayed on an oscilloscope, filtered, and fed into an audio monitor.

Multiple electrode penetrations were made in the SI cortex and in neighboring cortical areas. The recording sites were typically separated by 1-2 mm except in regions of particular interest, which were mapped at $0.5 \mathrm{~mm}$ intervals. At each recording site, the locations of somatic sensory receptive fields eliciting responses were identified, and the responsiveness of the units was characterized qualitatively. Neurons were categorized as having either "cutaneous" or "deep" receptor input. A neuron was defined as cutaneous if it could be clearly activated by a slight movement of hairs or by a light touch of the glabrous skin within the receptive field. Neurons identified as having deep receptor input were unresponsive to such tactile stimulation but could be activated by manipulation of the underlying musculature and associated tissues. No attempt was made to identify additional submodality types, such as fast and slowly adapting cutaneous responses (Sretavan and Dykes, 1983) or muscle spindle responses (Landgren and Silfvenius, 1969; Silfvenius, 1970). Recording sites of interest were indicated on the photomicrograph of the cortical surface using visible blood vessels as landmarks, and selected sites were marked by pushing the microelectrode to a depth of $6-8 \mathrm{~mm}$ below the cortical surface. Sites for tracer injections were chosen on the basis of electrophysiological mapping. Tracer was deposited by pressure injections from micropipettes with tip diameters of 20-30 $\mu \mathrm{m}$. In a single cat, the lectin PHA-L (Gerfen and Sawchenko, 
1984) was deposited electrophoretically at several cortical depths from an electrode ( $30 \mu \mathrm{m}$ tip) with a $5 \mu \mathrm{A}, 7 \mathrm{sec}$ on-7 sec off current (Graybiel and Devor, 1974).

\section{Anatomical analysis}

Following survival times of $48 \mathrm{hr}$ (with the exception of case CS-22, which had a $9 \mathrm{~d}$ survival time following a ${ }^{35} \mathrm{~S}$-methionine injection), animals were perfused with $2-3 \%$ glutaraldehyde or (for cases requiring immunohistochemistry) $4 \%$ paraformaldehyde in $0.1 \mathrm{M}$ dibasic $\mathrm{PO}_{4}$ buffer. In some instances, $2.5-5 \%$ sucrose was added to the fixative. The brains were washed overnight in a $20-30 \%$ sucrose- $0.1 \mathrm{M} \mathrm{PO}_{4}$ buffer solution, frozen in dry ice, and cut at $30-40 \mu \mathrm{m}$ in the transverse plane on a sliding microtome. Serially adjoining sections were processed to demonstrate injected tracers and histochemical markers. The histological proccdurcs cmploycd arc outlined briefly below. Table 1 specifies the protocols for individual cases.

\section{Autoradiography}

Mounted defatted sections were dipped in Kodak NTB-2 emulsion diluted $1: 1$ in $0.1 \%$ Dreft detergent solution (Cowan et al., 1972; Hendrickson et al., 1972). Sections were developed in Kodak D-19 following exposure times of 3-8 weeks and were then stained for Nissl substance with cresylecht violet

\section{HRP histochemistry}

Sections were processed for HRP with tetramethyl benzidine as the chromogen. The original procedure of Mesulam (1978) was modified by using an $\mathrm{H}_{2} \mathrm{O}_{2}$ concentration of $0.005 \%$ and by changing the incubation solution every 3-10 min over a period of $20-90 \mathrm{~min}$ (Illing and Graybiel, 1985). After incubation, the sections were mounted from a $0.01 \mathrm{~m}$ acetate buffer, dried, passed rapidly through increasing concentrations of alcohol, defatted with xylene, and coverslipped with Permount.

\section{Enzyme histochemistry}

Sections were incubated for AChE activity by a modified GeneserJensen and Blackstad (1971) protocol in an acetylthiocholine iodide solution containing ethopropazine (Parsidol, Warner-Chilcott) as pseudocholinesterase inhibitor. In 1 case, sections were stained for NADPH diaphorase activity by the protocol of Sims et al. (1974) for times sufficient to demonstrate striosomes (Sandell et al., 1986).

\section{Immunohistochemistry}

Immunoreactivity to rabbit anti-SP antiserum $6 \mathrm{H}$ from Dr. R. Ho was identified by the peroxidase-antiperoxidase method (Sternberger, 1979) according to the "protocol B" procedure described elsewhere (Graybiel and Chesselet, 1984). In 1 cat, enkephalin-like immunoreactivity (antiserum R176 against met-enkephalin, at 1:600, from Dr. R. P. Elde) and somatostatin-like immunoreactivity (antiserum S320 against SOM 28 $(1-12)$ at 1:1000, from Dr. R. Benoit) were demonstrated with similar protocols.

Sections were inspected with bright- and dark-field illumination. For the sections reacted for HRP, crossed polarizers were inserted in the light path to enhance the visibility of HRP-positive fibers (Illing and Wässle, 1979). Patterns of tracer labeling were charted at low magnification $(\times 12-25)$ with the aid of a drawing tube. Comparisons were made between patterns visible in neighboring sections by recording local vascular profiles on the initial chart, then aligning these with the corresponding blood vessels visible in the adjoining section and making a plot of tracer patterns in the second section. In selected cases, sections were photographed and then charted individually from the photographic negatives at appropriate magnifications. Injection sites were charted with the drawing tube and reconstructed. The borders of the injection sites had to be determined by eye according to staining or labeling intensity. These borders were then charted in relation to the electrophysiological maps by reference to the tracts of the injection pipette, marked microelectrode penetrations, and sulcal patterns.

\section{Results}

Physiology of primary somatic sensory cortex

Neurons in area SI were readily activated by gentle cutaneous stimulation and had well-defined receptive fields. The recon- structed somatic sensory maps, although based on a fairly low (typically 1-2 mm) density of electrode penetrations, resembled those described previously in suggesting (1) the presence of a single cutaneous representation of the body situated rostral and roughly parallel to the ansate sulcus (Felleman et al., 1983; Sretavan and Dykes, 1983) and (2) the presence of a second body map representing deep receptor input lying rostrally adjacent to the cutaneous field (Sretavan and Dykes, 1983). In accord with Felleman et al. (1983) and Kaas (1983), we term the primary cutaneous somatic sensory representation as comprising the SI cortex and the rostrally situated deep representation as comprising area $3 a$.

Figure 1 shows the most comprehensive cutaneous map obtained in this study (from case CS-21). Viewed from above, the composite cutaneous representation forms a $\mathrm{V}$-shaped band that runs roughly mediolaterally, with its apex directed caudally. The representations of rostral body parts are situated lateral to the representations of more caudal body parts. The anterior limits of the cutaneous field were determined by placing electrode penetrations at successively more rostral sites. An abrupt shift from cutaneous to deep responsiveness appeared consistently along the border between SI and area 3a. Other neighboring cortical areas were not explored in detail except at their borders with areas SI and 3a. These borders were usually characterized by a reduction in neuronal responsivity or a reversal in the progression of receptive field location. In reconstructing recording and injection sites in relation to cortical subdivisions, we relied primarily on such physiological criteria, with cytoarchitectonic features serving only as complementary guides (see Hassler and Muhs-Clement, 1964; and Fig. 12).

\section{Corticostriatal projections from single loci in the primary cutaneous somatic sensory cortical field}

All tracer injections placed in the SI cortex labeled afferent-fiber clusters in the dorsolateral corner of the ipsilateral caudate nuclcus, in the dorsal putamen, and in the cell bridges in between. Examples of clusters labeled by single tracer deposits in physiologically identified sites in SI are shown in Figure 2.

Regardless of the body part represented at the site of injection, 1-4 intensely labeled patches could be identified within the SI projection field in individual sections. In size and cross-scctional shape, the labeled patches resembled histochemically defined striosomes: They formed disks, rings, and branched bands $0.1-$ $0.6 \mathrm{~mm}$ wide and up to $2 \mathrm{~mm}$ long. Heavily labeled patches tended to lie in a larger region of weak labeling. Often the patches seen at the periphery of the projection field were less strongly labeled than those near the center. The distance between patches varied, but separations of up to $1 \mathrm{~mm}$ occurred. Larger injections tended to label more patches that subtended larger anteroposterior extents than the patches labeled by small injections. There was no clear tendency for patch size to vary systematically with the body part represented at the site of injection. Like striosomes, however, the afferent-fiber patches seemed to be larger rostrally than caudally.

The patches of labeling visible in single sections were traced through sets of closely spaced or serial sections in most cases. The labeled zones tended to be somewhat more extended along the anteroposterior axis than along the mediolateral axis of the striatum, but sometimes (as shown in Fig. $2 D$ ), elongated mediolateral tongues of label appeared in single cross sections. Patches separated from one another at one transverse level appeared sometimes to fuse together at another level, but in other instances isolated patches could be followed throughout their length without an indication that they contacted neighboring patches.

Individual afferent-fiber clusters usually had 1 or more zones of especially dense labeling within them (Fig. $3 \mathrm{~A}$ ). The intensity 

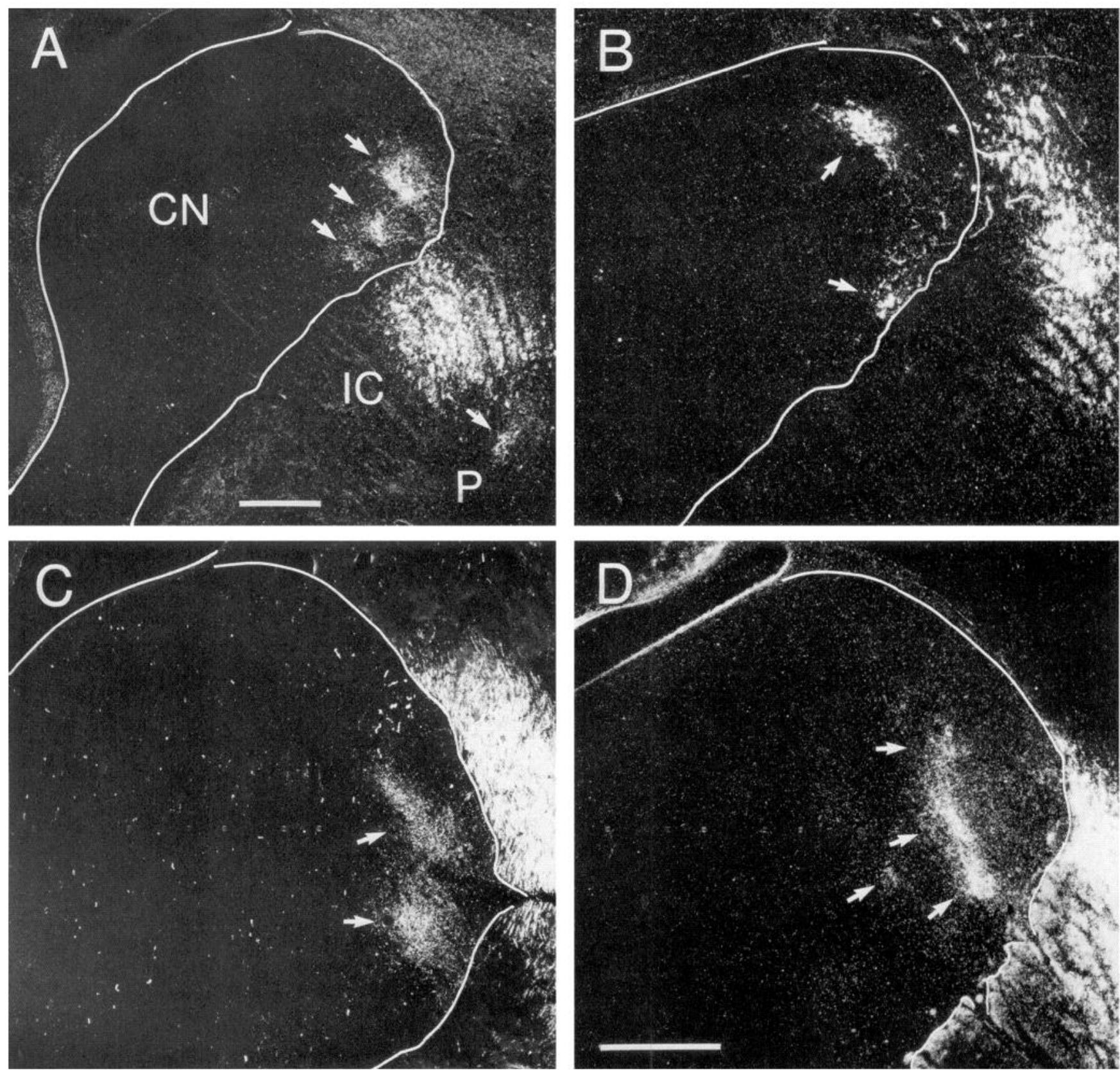

Figure 2. Examples of striatal labeling elicited by single injections in cutaneous body representation of area SI. Each panel shows dark-field photomicrograph of cross section through ipsilateral striatum. Tracer labeling appears white and in each photograph is densest in the internal capsule (IC). The borders of the caudate nuclei are indicated by white lines drawn on the photographic prints. $C N$, caudate nucleus; $P$, putamen. $A$, Autoradiographic labeling following a single injection into the vibrissae-lip representation of case CS-19. Injection site is shown in Figure $12 A$. Arrows indicate 3 labeled afferent-fiber clusters in the caudate nucleus and a fourth cluster in the putamen. $B$, Patches of WGA-HRP labeling from a single injection into the forepaw representation of case CS-20 (shown in reverse for ease of comparison with $A, C$, and $D$ ). Injection site is shown in Figure 12B. Arrows point to 2 patches of labeling. $C$, Arrows point to WGA-HRP labeled afferent-fiber clusters in the dorsolateral caudate nucleus seen after an injection into the forearm representation of case CS-8. D. Autoradiographically labeled patches seen following a single injection in the trunk representation of case CS-7. Arrows point to densifications within a mediolaterally elongated patch and to a weak patch ventral to this. Scale bar: $A, 1 \mathrm{~mm} ; B-D, 1 \mathrm{~mm}$.

of labeling gradually diminished toward the periphery of the patches, but occasionally a fairly sharp boundary occurred between a labeled patch and an adjoining region of scant labeling. Frequently, individual patches appeared to have within them a zone avoided by most of the incoming labeled afferents (Fig. $3 A$ ). At high magnification, fine lattice patterns could be seen within the patches, and streamers of labeled fibers sometimes appeared to radiate out from their borders (see Fig. $3 A$, arrows).
In 1 case (CS-22), we injected the lectin PHA-L together with ${ }^{35} \mathrm{~S}$-methionine into the cutaneous forepaw digit 3 representation so that we could study the fiber morphology of the somatic sensory afferents (Gerfen and Sawchenko, 1984) and directly compare the pattern of labeling obtained with the 2 tracers. The density of PHA-L labeling was not great, but patches of dense ${ }^{35} \mathrm{~S}$-methionine labeling overlapped regions in which the highest concentration of fibers and varicosities labeled with PHA-L 

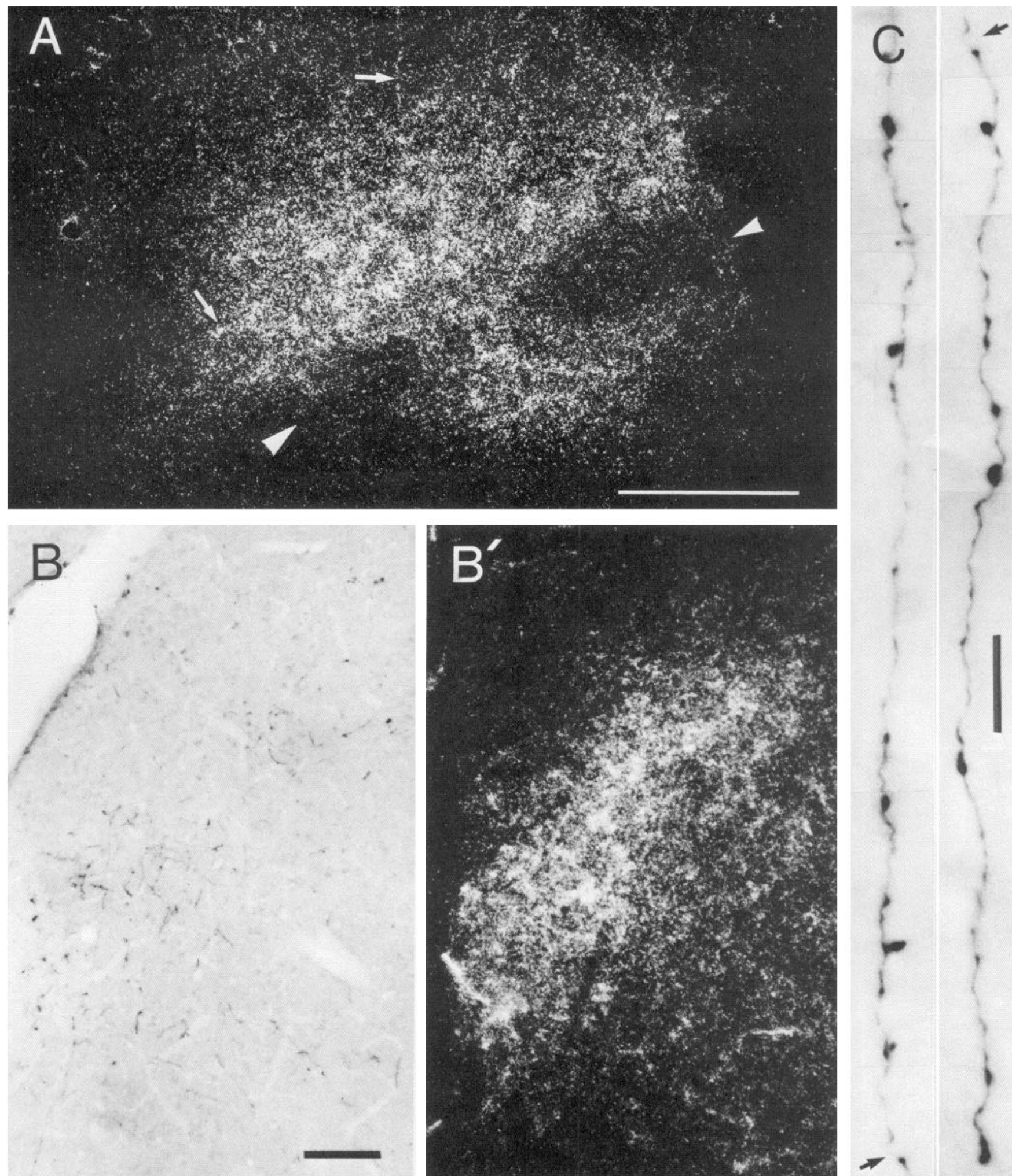

Figure 3. High-magnification view of somatic sensory corticostriatal projections. $A$, Single patch in the caudate nucleus labeled following a WGAHRP injection into the deep receptor forearm representation of case CS-5. Injection site is shown in Figures $7 \mathrm{~A}$ and $12 \mathrm{E}$. Arrowheads point to conspicuously weakly labeled holes protruding into the patch. Note the latticework of label visible in the patch. Arrows point to representative streamers of label at the edge of the patch. Scale bar, $0.5 \mathrm{~mm} . B$ and $B^{\prime}$, Serial-section comparison of labeling in the caudate nucleus seen after a combined ${ }^{35} \mathrm{~S}$-methionine and PHA-L injection into the cutaneous forepaw digit 3 representation of case CS-22. PHA-L (B) and ${ }^{35} \mathrm{~S}-\mathrm{methionine}$ $\left(B^{\prime}\right)$ labeling both appear in the patch, although the ${ }^{35}$ S-methionine labeling is much stronger. $C$, Montage of PHA-L labeled fiber near the dense core of a PHA-L labeled region corresponding to an autoradiographically labeled patch. Two adjoining segments of the fiber are shown, with the small arrows indicating common points in the 2 panels. Note varicosities along the fiber. Scale bar: $B$ and $B^{\prime}, 0.1 \mathrm{~mm} ; C, 10 \mu \mathrm{m}$. 

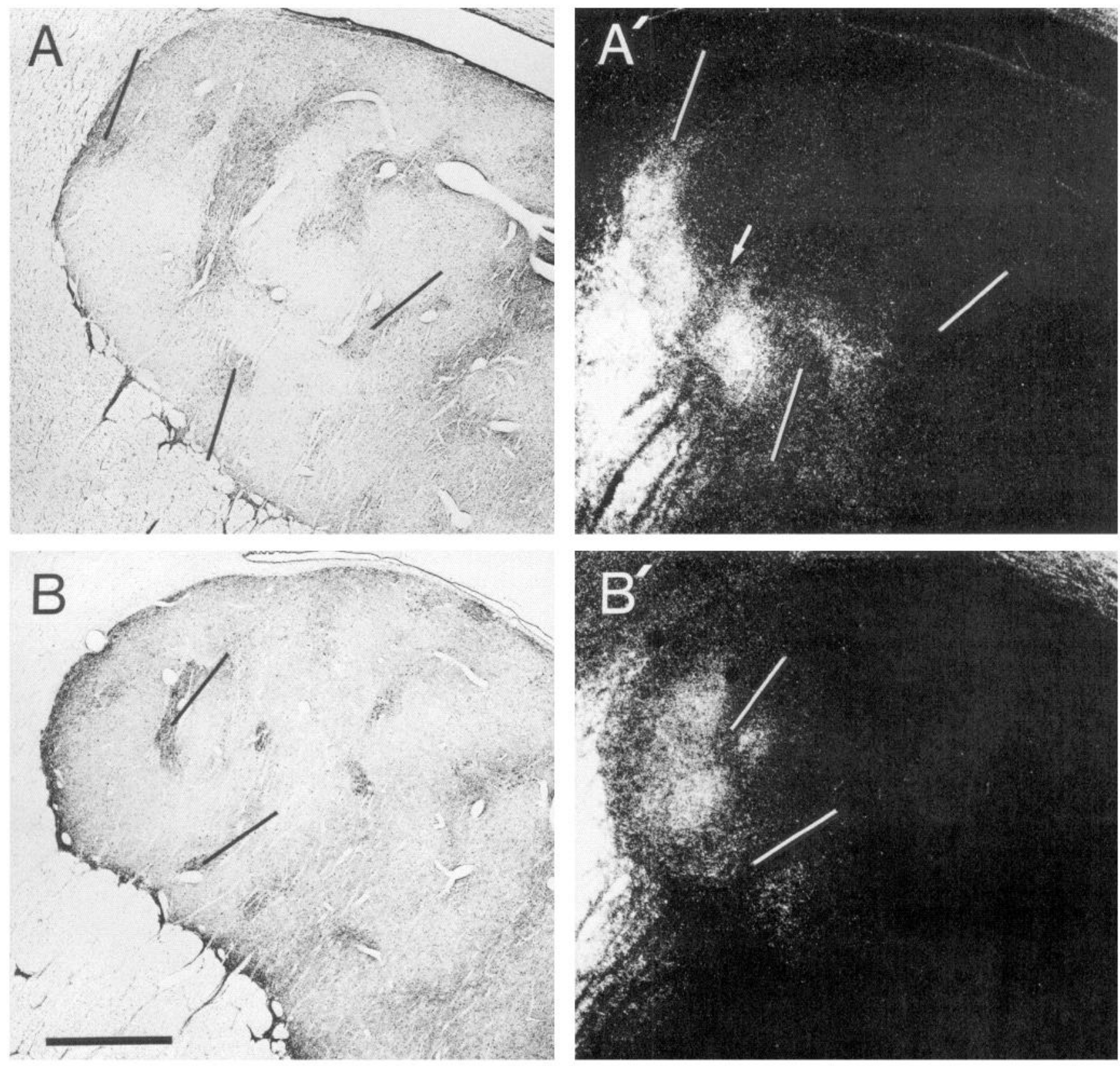

Figure 4. Relation of the somatic sensory corticostriatal projections to striosomes in 2 cases, CS-18 $\left(A, A^{\prime}\right)$ and CS-21 ( $\left.B, B^{\prime}\right)$. The photomicrographs in $B$ and $B^{\prime}$ have been reversed for ease of comparison with $A$ and $A^{\prime} . A$ and $B$, SP-rich striosomes visible in single cross sections. The SPimmunoreactive striosomes appear dark. $A^{\prime}$ and $B^{\prime}$, Dark-field photomicrographs of sections serially adjacent to those shown in $A$ and $B$, showing clustered somatic sensory corticostriatal projections. Labeling in $A^{\prime}$ resulted from 4 large, confluent ${ }^{35}$ S-methionine injections that involved both the deep and cutaneous shoulder-arm-forepaw representations. Labeling in $B^{\prime}$ resulted from injection of nearly the full extent of the cutaneous representation in SI ${ }^{35} \mathrm{~S}$-methionine. Injection site is shown in Figure $1 A$. The lines in $A$ and $A^{\prime}$, and in $B$ and $B^{\prime}$, point to the corresponding points in the 2 pairs of sections. Note the sharp diminution of afferent fiber labeling at the sites of striosomes (compare the corresponding sites in the 2 pairs of sections marked by lines).

were found (Fig. 3, $B, B^{\prime}$ ). Both the fragmentation of PHA-Lpositive fibers in regions of heavy ${ }^{35} \mathrm{~S}$-methionine labeling and the presence of PHA-L-labeled varicosities in these regions suggested the presence of corticostriatal terminations in the patches.
PHA-L-positive fibers (Fig. 3C) followed through the striatal parenchyma were thin, branched only rarely, and contained unevenly distributed varicosities that were often located at the ends of short twigs (DiFiglia et al., 1978).

Figure 5. Relation of projections from 2 cutaneous body part representations. $A$, Dorsolateral view of the right hemisphere in case CS-10, illustrating injection sites in relation to the somatic sensory map of SI; a single injection of WGA-HRP in the forepaw digit 4 representation. Filled circles, points of cutaneous responsiveness; filled triangles, points of deep-receptor responsiveness. Photomicrographs of injection sites are shown in Figure 12, C and D. B. Sample of somatic sensory receptive fields recorded in case CS-10. Same symbols and conventions as in Figure 1. Asterisks denote the receptive fields recorded at the center of the 2 injection sites. $C$ and $C^{\prime}$, Photomicrographs of serially adjoining sections illustrating 

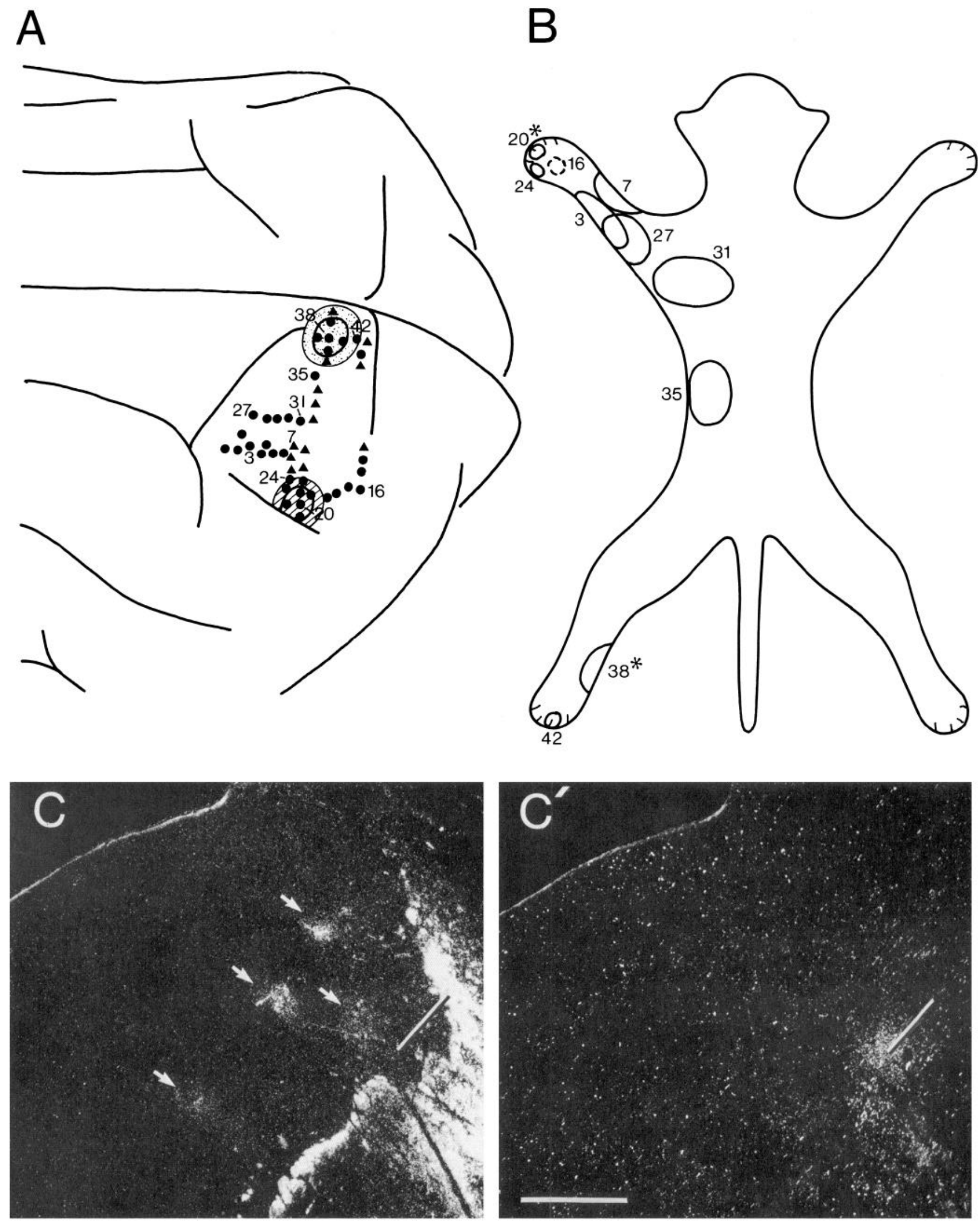

striatal labeling produced by the injections in case CS-10. $C$, Labeling pattern following ${ }^{35} \mathrm{~S}$-methionine injection into the hindpaw representation (arrows point to 4 labeled patches). The position corresponding to the labeled patch in $C^{\prime}$ is marked by a line. $C^{\prime}$, WGA-HRP labeling from the cortical forepaw-digit 4 representation. The center of the labeled patch is marked by a line. Note the medial shift of "hindpaw patches" relative to "forepaw patch." Scale bar, $1 \mathrm{~mm}$. 


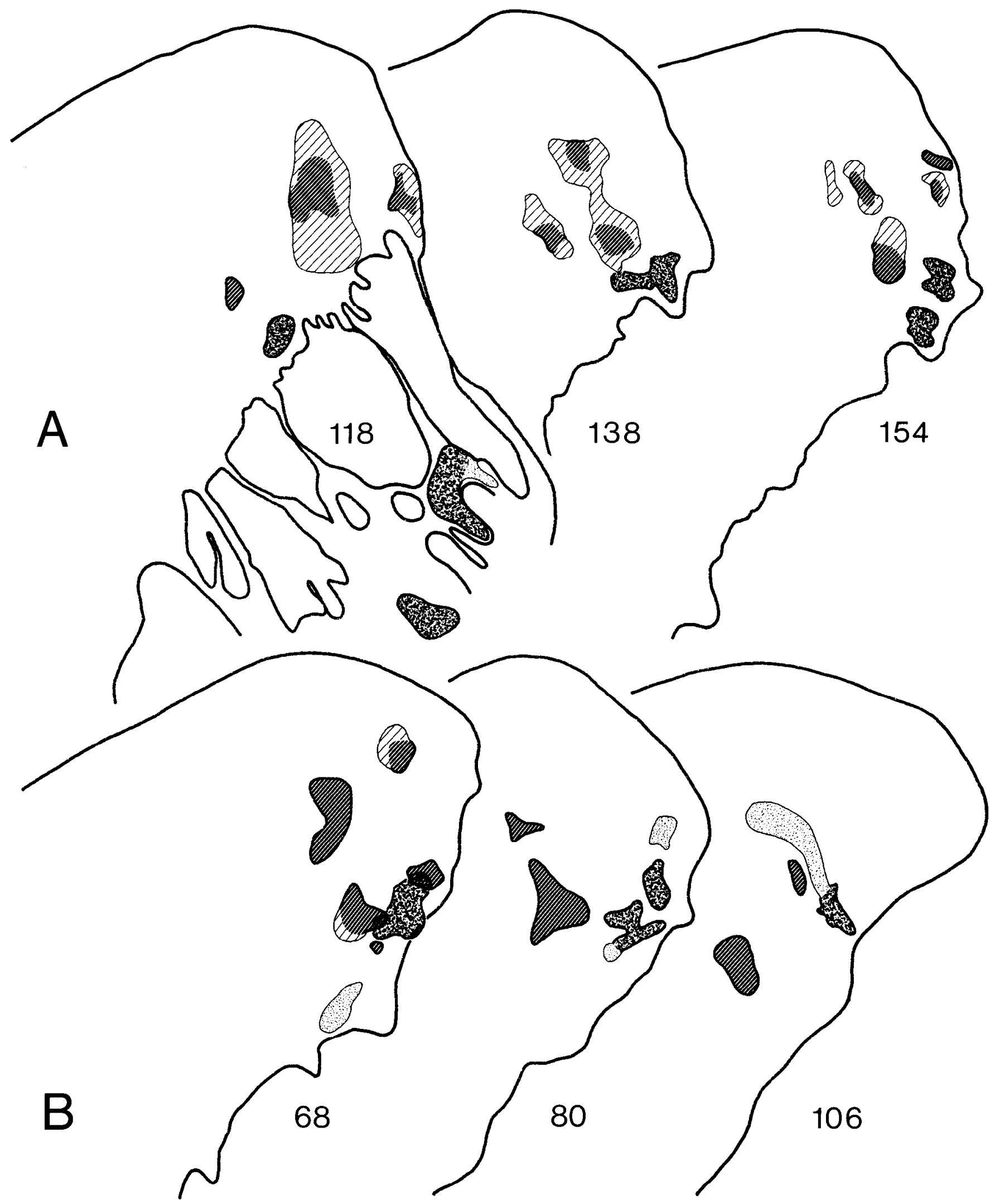

Figure 6. Organization of the cutaneous corticostriatal projections labeled in 4 experiments in which progressively more closely spaced body part representations in area SI were injected with distinguishable tracers. $A-D$, Each panel shows 3 overlay chartings of cross sections at different anteroposterior levels. Section numbers are indicated to give the distance between the charts and are numbered relative to the rostral end of the caudate nucleus (0); sections are $40 \mu \mathrm{m}$ thick. In each case, part of the forepaw representation was injected, and the projections from these sites are shown by stippling. Hatched symbols denote projections labeled from the other sites representing body parts progressively closer to the forepaw sites in the series $A-D$. Each composite chart was produced by superimposing the individually charted patches from 2 consecutive sections processed 


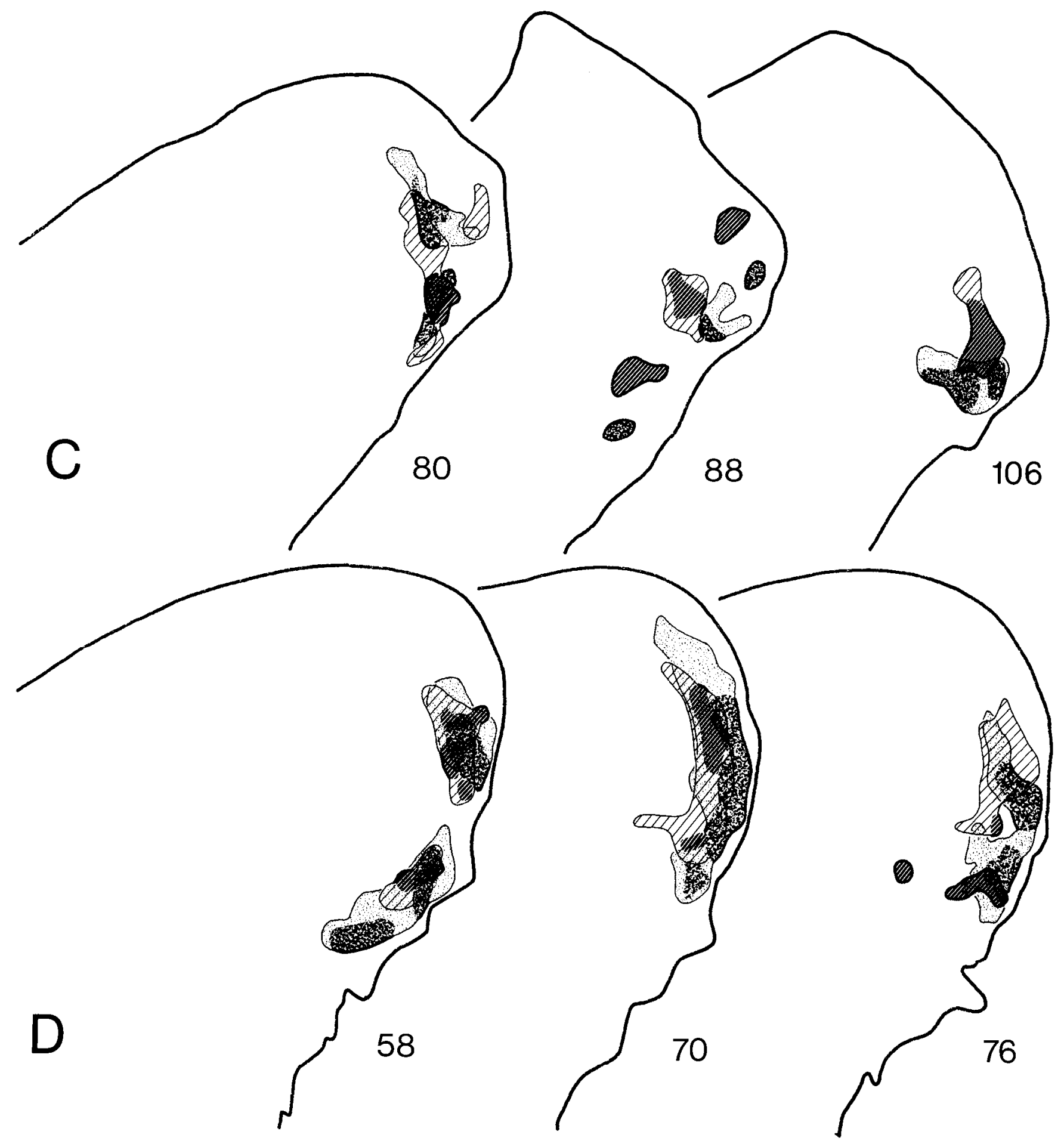

for a different tracer. Darker symbols delineate the most intensely labeled regions of the afferent-fiber patches; lighter symbols delineate the more faintly labeled regions. $A$, Case CS-10, which received pairwise injections of WGA-HRP into the forepaw digit 4 representation and ${ }^{35} S-m e t h i o n i n e$ into the hindpaw representation (injection sites shown in Figs. $5 ; 12, C, D$ ). $B$, Labeling pattern in the right striatum of case CS-20 following paired injections of WGA-HRP into the forepaw digit 5 representation and ${ }^{35} S$-methionine into the trunk representation of its right hemisphere. $C$, Labeling in the left striatum of case CS-20 following WGA-HRP and ${ }^{35}$ S-methionine injections into the elbow and forepaw representations, respectively, of the left hemisphere. $D$, From case CT-2, in which WGA-HRP and ${ }^{35}$-methionine were injected into the forepaw digits $4 / 5$ representation and the forepaw digit 5 representation, respectively. (The 2 injection sites are separated by 2 mm cortical distance.) Note the orderly relative shift of the 2 sets of innervated patches as the body parts represented at the paired injection sites become closer, a pattern indicating composite somatotopy of the striatal district. 
Relationship between somatic sensory fiber clusters and striosomes

From the similarity in appearance of the SI corticostriatal patches and histochemically defined striosomes, one might have inferred that the somatic sensory projections were actually confined to the striosomal system. To investigate this possibility, we compared the distribution of the somatic sensory projections with the patterns of striosomal staining visible with a variety of histochemical methods (see Table 1). In the dorsolateral corner of the caudate nucleus corresponding to the SI projection field, the clearest demonstration of striosomes was provided by immunohistochemistry for SP (Beckstead and Kersey, 1985; Graybiel and Chesselet, 1984). Crisply bounded striosomes containing SP-positive neuropil and numerous SP-immunoreactive neurons appeared in a field of weaker immunostaining. When this pattern was compared with the distribution of the corticostriatal fiber clusters labeled in neighboring sections, it was clear that the 2 sets of patches avoided each other. This was truc regardless of which body part or somatic sensory submodality was represented at the site of injection.

This avoidance relationship is illustrated in Figure 4. In case CS-18 (Fig. 4, $A, A^{\prime}$ ), cortex corresponding to the entire arm representation of both the deep receptor (area 3a) and cutaneous (SI) maps was infiltrated with ${ }^{35}$ S-methionine. In case CS-21 (Fig. 4, $B$ and $B^{\prime}$ ), extensive injections of both WGA-HRP and ${ }^{35}$ S-methionine were made throughout the entire cutaneous body map of the SI cortex. The injection sites and composite physiological map are illustrated in Figure 1. None of the clusters of labeled somatosensory fibers coincided with SP-rich striosomes, which appeared lateral and medial to and in the midst of the zones of innervation.

\section{The body map in the striatum}

The cross-sectional shapes and locations of the somatic sensory patches varied at different anteroposterior levels within the striatum of individual hemispheres, which made it difficult to construct a reliable composite somatotopic map by making crossanimal comparisons. We addressed this problem by injecting, in the same animal, 2 differentiable tracers into SI cortex corresponding to different parts of the body representation. We then compared the distributions of the 2 labeled fiber projections within the striatum.

Figure 5 shows an example from case CS-10, in which WGAHRP was injected into the cutaneous forepaw digit 4 representation of SI (injection site shown in Fig. 12C) and ${ }^{35}$ S-methionine was injected into the cutaneous hindpaw representation of SI (injection site shown in Fig. 12D). The resulting labeling in the striatum is illustrated in 2 serially adjoining sections in Figure $5, C$ and $C^{\prime}$. A row of 3 clearly delineated patches was labeled from the hindpaw representation ("hindpaw" patches), with a fourth, more diffuse patch lateral to this row (Fig. 5C). The projection from the forepaw digit 4 representation (Fig. $5 C^{\prime}$ ) appeared as a single, well-circumscribed "forepaw" patch and a second weak "forepaw" patch in a cell bridge between the caudate nucleus and putamen. As can be seen, there is a clear medial displacement of the "hindpaw" patches relative to the "forepaw" patches. There is no obvious pairing between individual "hindpaw" and "forepaw" patches, a pattern that might have been expected if there were multiple, spatially separated body representations in the striatum.

These 2 points are further illustrated in Figure 6, which shows the relationship between the corticostriatal projections from pairs of cortical regions representing different body parts labeled by the double-tracer method in 4 hemispheres. In each case, the forepaw or forepaw-digit representation of SI was injected with 1 tracer. Progressively more closely spaced body part representations were injected with the second tracer. The spacings ranged from hindpaw-forepaw to adjoining forepaw digits. Each chart in Figure 6 represents a composite of the drawings of the most intensely labeled parts of the patches visible in 2 serial sections processed, respectively, for the 2 tracers injected.

The findings in these experiments clarified several points about the ordering of the somatic sensory corticostriatal mapping. First, despite the complex and irregular shapes of the cutaneous afferent-fiber clusters, they were arranged in a systematic mediolateral order with respect to each other. This was reflected by the fact that in each case, including the cat in which cortical zones corresponding to closely neighboring parts of the forepaw digit representation were injected (Fig. $6 D$ ), it was possible to distinguish the corticostriatal projections from more caudal body part representations by their more medial location within the striatum. This systematic relative spacing indicates considerable resolution in the representation of the cutaneous body map in the striatum. Second, although only a rough delineation of the map was provided in our experiments, certain topological distortions were indicated by the patterns of projection. A consistent finding was a gradual rotation in the axis of orientation of the map at different anteroposterior levels. For example, in the case shown in Figure 6B, the set of "trunk" patches was located dorsomedially to the "forepaw" patches at rostral levels in the striatum, but at more caudal levels the "trunk" patches shifted their relative positions so as to become ventromedial to the "forepaw" patches. Another type of distortion, perhaps representing an anisotropy in the map, was suggested by the great variability in the separation between the 2 sets of patches at different anteroposterior levels and between different members of a set of patches labeled with a single tracer. Further, the border region between the 2 sets of labeled patches was occasionally deeply curved to produce a convexity facing medially, as if the body map in the striatum had been differentially stretched.

\section{Relationship between corticostriatal afferents representing different somatic sensory submodalities}

From the findings presented so far, it might be surmised that the extrastriosomal matrix in the SI projection field is "built up" by abutting, in an orderly fashion, sets of patches representing consecutive body parts. However, in studying the relationship between projections labeled by injection sites in the deep receptor and cutaneous somatic sensory maps of areas $3 \mathrm{a}$ and SI, we encountered patterns of projection that suggest that this view is overly simplified and that another type of mapping rule, one of interdigitation of different sets of inputs, should also be included as an organizational feature of the striatal matrix.

Two examples of such mapping relationships are illustrated in Figures 7-10. In case CS-5 (Figs. 7, 8), an attempt was made to inject matched body part representations in areas 3 a (deep) and SI (cutaneous) with distinguishable tracers. A single injection of WGA-HRP was made in the deep receptor forearm representation, and a single injection of ${ }^{35} \mathrm{~S}$-methionine was made in the cutaneous forearm representation (Figs. $7 ; 12, E, F$ ). The 3 matched pairs of photographs in Figure 8 illustrate the patterns of intrastriatal labeling found in serial sections. The corticostriatal projection traced from area $3 a$, like that from SI, was strictly ipsilateral. This suggested that the injection site in area 3a did not spread extensively into the adjoining motor cortex, which has a bilateral projection to the striatum (Künzle, 1975).

Both corticostriatal projections consisted of a broken field of labeled zones that formed patches in individual cross sections. The "deep receptor" patches labeled from the injection site in area 3 a were similar to the "cutaneous" patches labeled from the SI site in their range of cross-sectional shapes and sizes. The 2 sets of patches were also located in the same general region of the striatum. The more weakly labeled regions in the 2 projection systems usually overlapped. However, close inspection of the labeling patterns in carefully aligned pairs of serial sections 
A
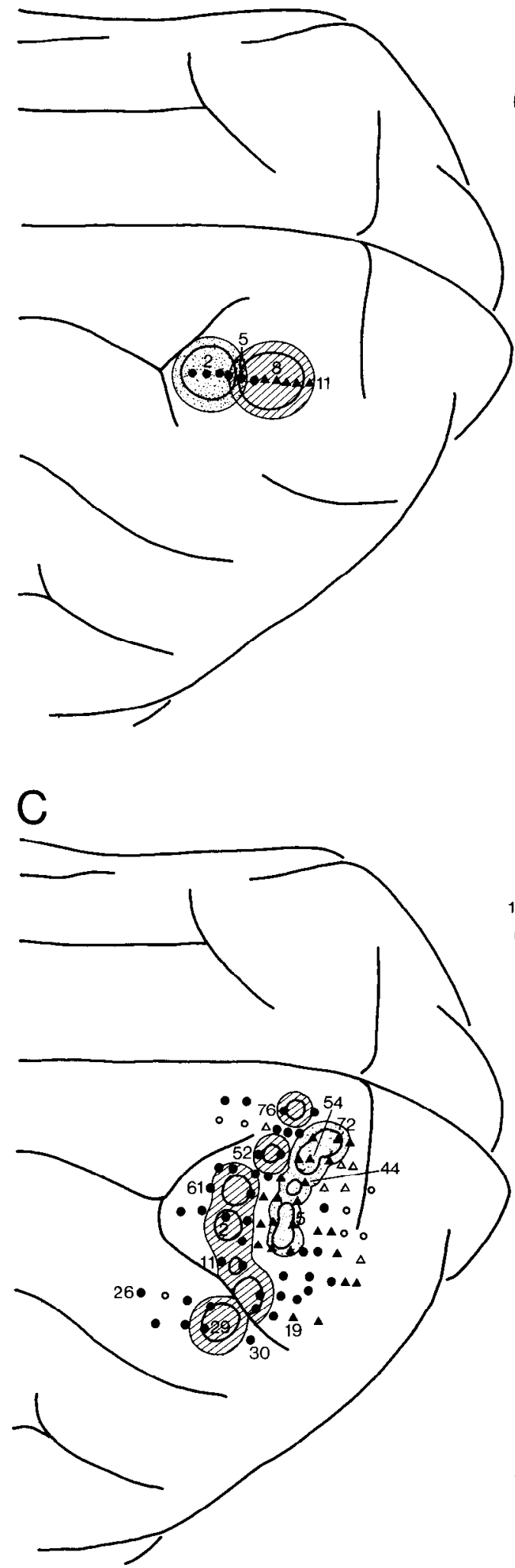

B

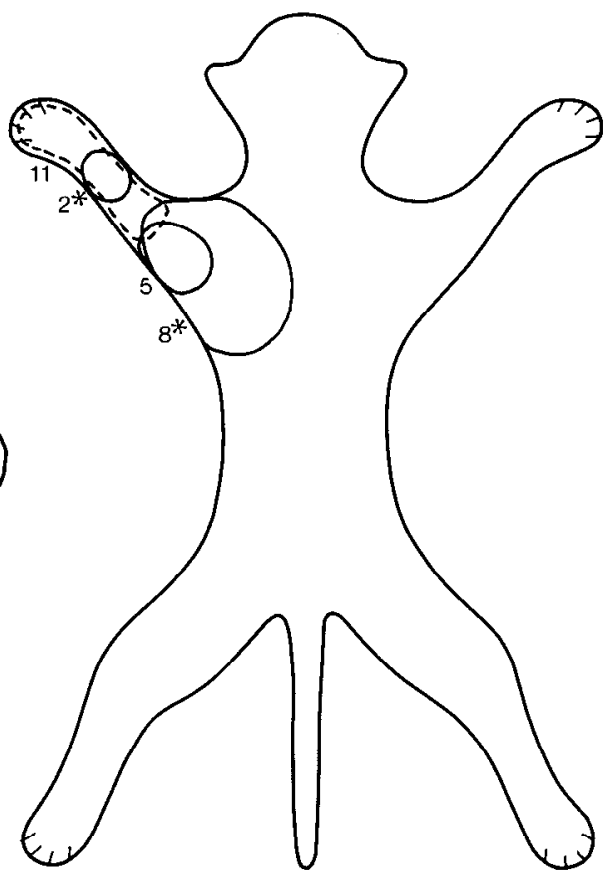

Figure 7. Cases of paired injections of distinguishable tracers into the cutaneous (SI) and deep-receptor (area 3a) representations of the somatic sensory cortex. $A$ and $B$, Case CS-5, which received paired injections of WGA-HRP into the deep-receptor forearm representation of area $3 \mathrm{a}$ and ${ }^{35} \mathrm{~S}$-methionine into the cutaneous forearm representation of area SI $(A)$. Photomicrographs of the injection sites are shown in Figures $12 E$ (WGA$\mathrm{HRP}$ ) and $12 F$ ( ${ }^{35} \mathrm{~S}$-methionine). Somatic sensory receptive fields of selected recording sites in $B$ are keyed by unit numbers to those shown in $A$. Symbols and conventions as in Figure 5. $C$ and $D$, Case CS-14, which received multiple injections of ${ }^{35} \mathrm{~S}-\mathrm{me}-$ thionine into the deep-receptor representation (area 3a) and multiple injections of WGA-HRP into the cutaneous representation (area SI). Injection sites are shown in Figure $12 G$ ${ }^{35} \mathrm{~S}$-methionine) and $12 \mathrm{H}$ (WGAHRP). Receptive fields at selected recording sites shown in $C$ are depicted in $D$. Unfilled triangles in $C$ indicate recording sites at which only weak responses to taps could be obtained. Otherwise, same symbols and conventions as in Figure 5 (filled circles, cutaneous responses; filled triangles, deep responses).

demonstrated that the most intense cores of the patches labeled with 1 tracer (Fig. 8, $A-C$ ) tended to be interleaved among the most intensely labeled cores of the patches labeled with the other tracer (Fig. 8, $A^{\prime}-C^{\prime}$ ). It was as though the area $3 \mathrm{a}$ and SI forearm representations had both been mapped onto the same discon- tinuous projection field but that, within this field, the zones of densest "deep" and "cutaneous" projection were displaced relative to one another.

The chartings of Figure $10 \mathrm{~A}$ indicate the range of spatial relationships encountered between the 2 sets of patches in indi- 

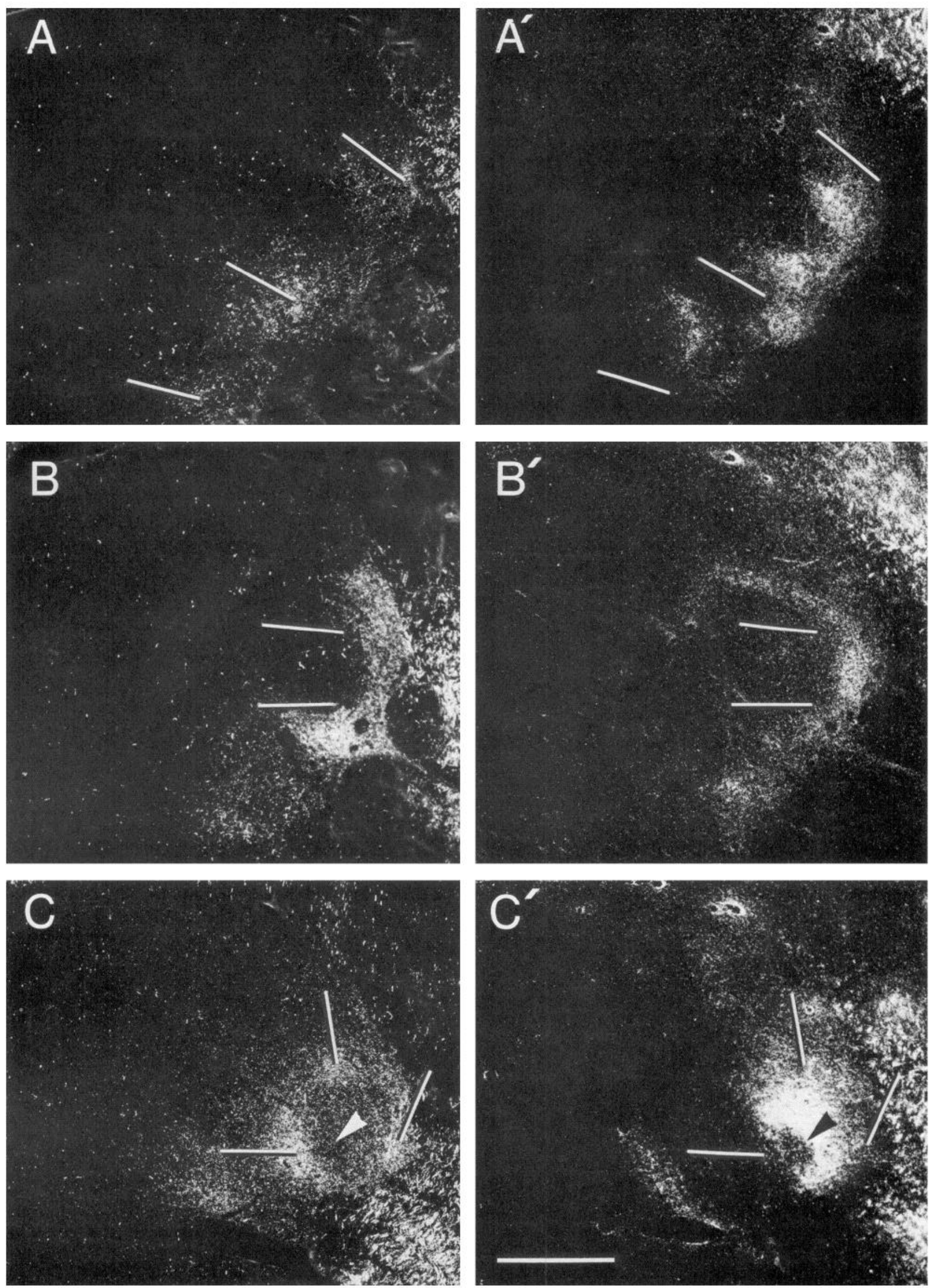

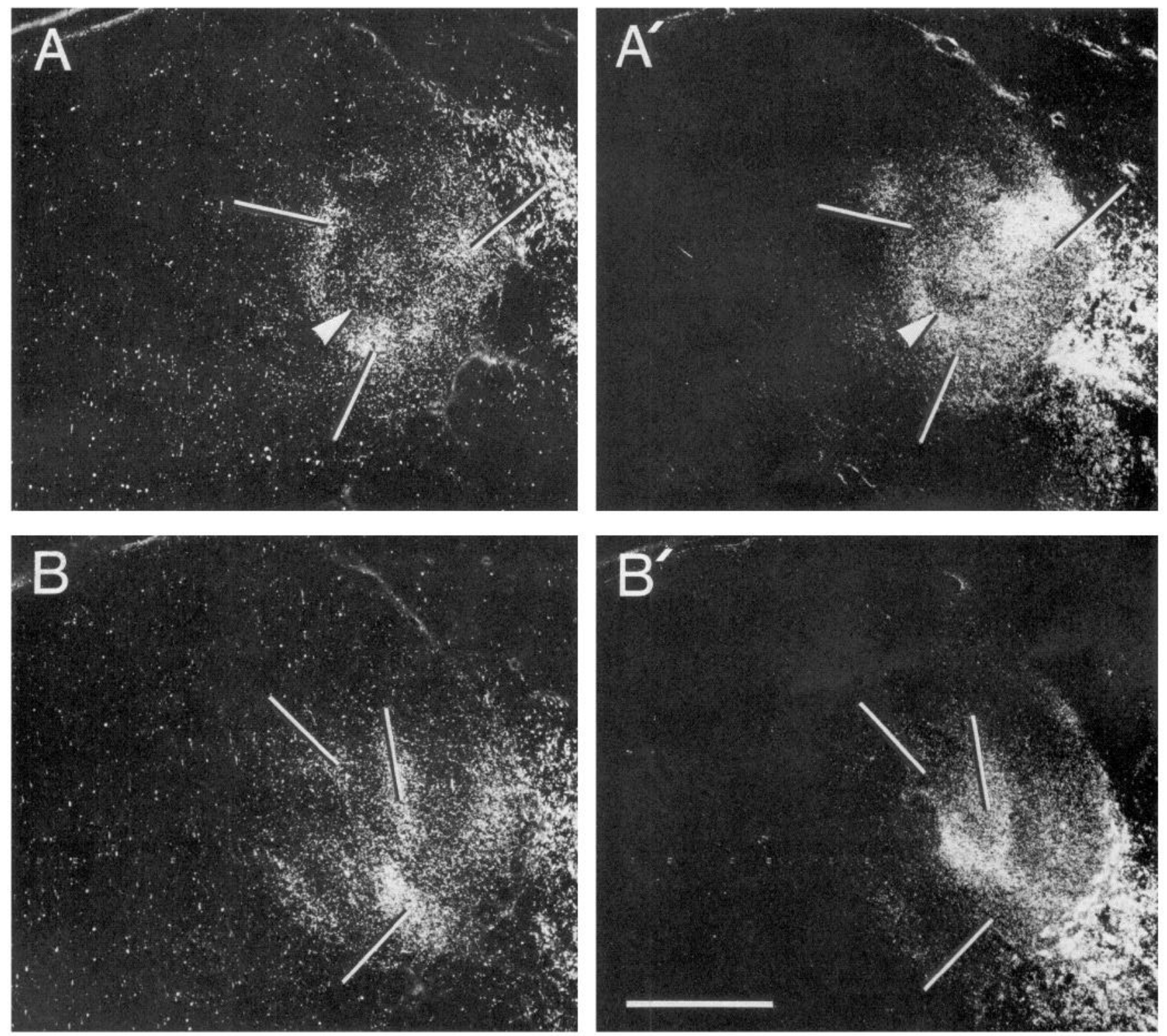

Figure 9. Pattern of labeling following the multiple injections of differentiable tracers into the deep receptor and cutaneous representations of case CS-14 (shown in Fig. $7 C$ ). $A$ and $B$, WGA-HRP labeling of cutaneous projections in cross sections through the caudate nucleus. $A^{\prime}$ and $B^{\prime},{ }^{35}$ Smethionine labeling of deep-receptor projections in sections serially adjoining those shown in $A$ and $B$. The lines indicate corresponding points in the serial section pairs. Note that, as in the case of the more restricted paired injections shown in Figure 8, the densest parts of the paired patches tend to interdigitate with each other, despite an overlap of weaker labeling and occasional partial overlaps of denser zones. Arrowheads point to corresponding zones of especially weak labeling. Scale bar, $1 \mathrm{~mm}$.

vidual cross sections from this case. At some levels, the relative displacement was more obvious then at others, and there were occasional instances of overlap of heavily labeled zones, but it was clear that the offset was a consistent feature of the 2 projections. Both of the fiber projections also occasionally avoided zones situated within their respective projection fields, producing sparsely labeled "holes" similar to those already described for the SI projection.

In case CS-14 (Fig. 9), we labeled as much as possible of the deep receptor and cutaneous body representations with distin-

Figure 8. Labeling pattern in the striatum following the paired single injections in the deep-receptor and cutaneous forearm representations in case CS-5 (shown in Fig. 7A). $A-C$, Labeling patterns in 3 cross sections through the caudate nucleus following injection of WGA-HRP into the deep-receptor forearm representation (shown in Figs. $7 A, 12 E$ ). $A^{\prime}-C^{\prime}$, Sections serially adjoining those shown in $A-C$ illustrating the labeling elicited by ${ }^{35} \mathrm{~S}$-methionine injection into the cutaneous forearm representation (shown in Figs. $7 A, 12 F$ ). The lines point to corresponding sites in the pairs of sections: In $A$ and $A^{\prime}$, lines mark the densest patches of labeling in $A$; in $B$ and $B^{\prime}$, lines mark the dorsal and ventral edges of the densely labeled patch in $B^{\prime}$; in $C$ and $C^{\prime}$, the lines mark the 3 most densely labeled patches in $C$. Note the pattern of avoidance between the most intense regions within the 2 sets of patches. Arrowheads in $C$ and $C^{\prime}$ point to a small patch avoided by both sets of afferents. $B$ and $B^{\prime}, 320 \mu \mathrm{m}$ caudal to $A$ and $A^{\prime} ; C$ and $C^{\prime}, 1.12 \mathrm{~mm}$ caudal to $A$ and $A^{\prime}$. Scale bar, $1 \mathrm{~mm}$. 


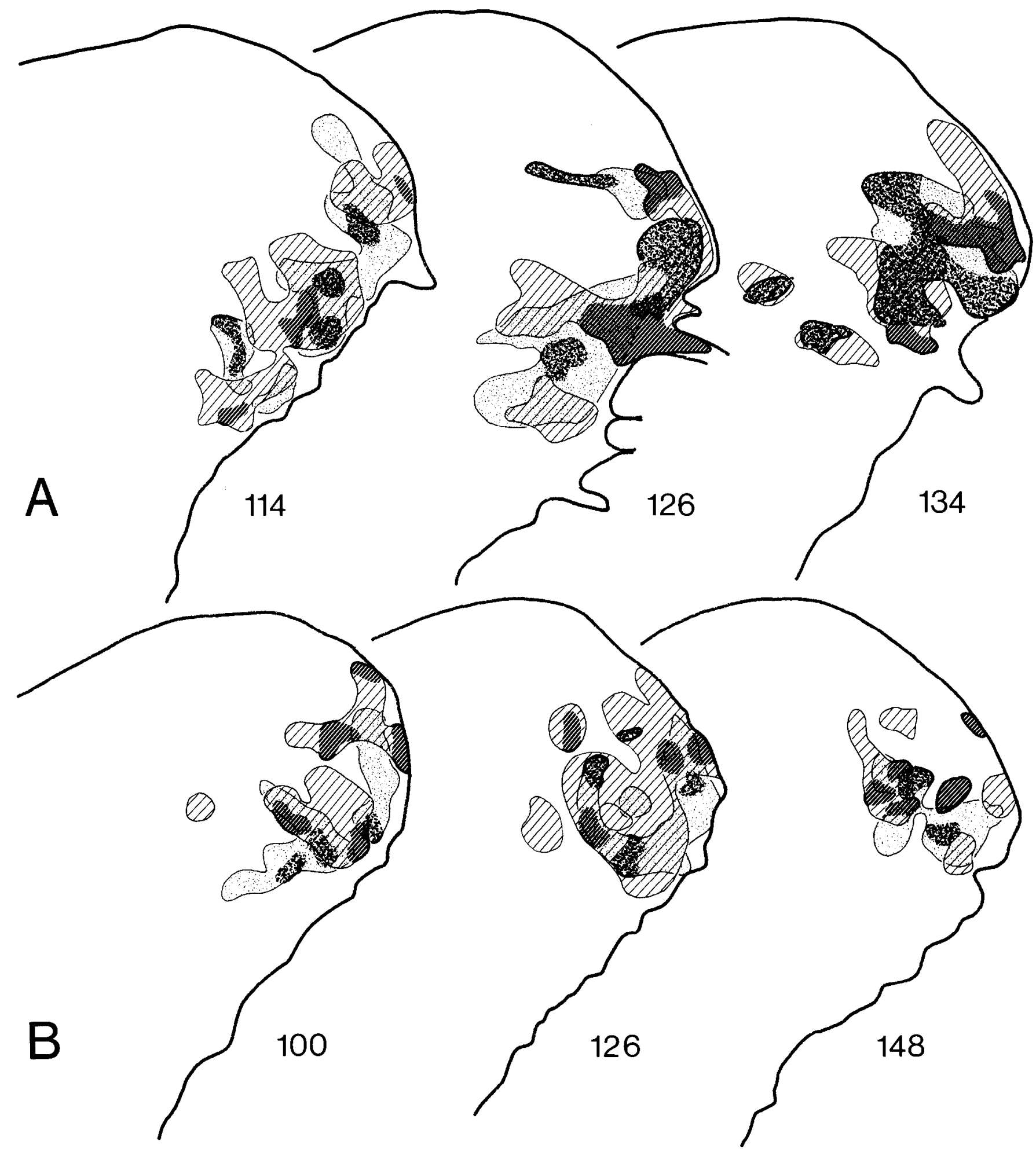

Figure 10. Spatial relationship between the deep-receptor and cutaneous corticostriatal projection systems seen in cases CS-5 $(A)$ and CS-14 $(B)$. For each set of drawings, stippled symbols represent cutaneous projections and hatched symbols represent deep-receptor projections. Dark stippling and hatching show densest labeling; lighter stippling and hatching, weaker labeling. The 2 projection systems labeled in each case are shown in composite overlay drawings. Sections are numbered with reference to the rostral pole of the caudate nucleus $(0)$. Sections are $40 \mu \mathrm{m}$ thick. The composite charts in $A$ show labeling from single paired injections into the cutaneous and deep representations of the forearm (cf. Figs. 7,8 ). The first chart illustrates the sections shown in the photographs of Figure $8, A, A^{\prime}$. The charts in $B$ illustrate labeling from large multiple injections into the deep-receptor and cutaneous representations (cf. Figs. 7, 9). The second chart of the set shows patterns from sections shown in Figure $9, B$ and $B^{\prime}$. Both the deep-receptor and cutaneous projections are broken up into patches. Note that in both cases the most densely labeled parts of the cutaneous and deep-receptor projections do not overlap or overlap only slightly. There is major overlap of the more weakly labeled parts of the 2 projection systems. 

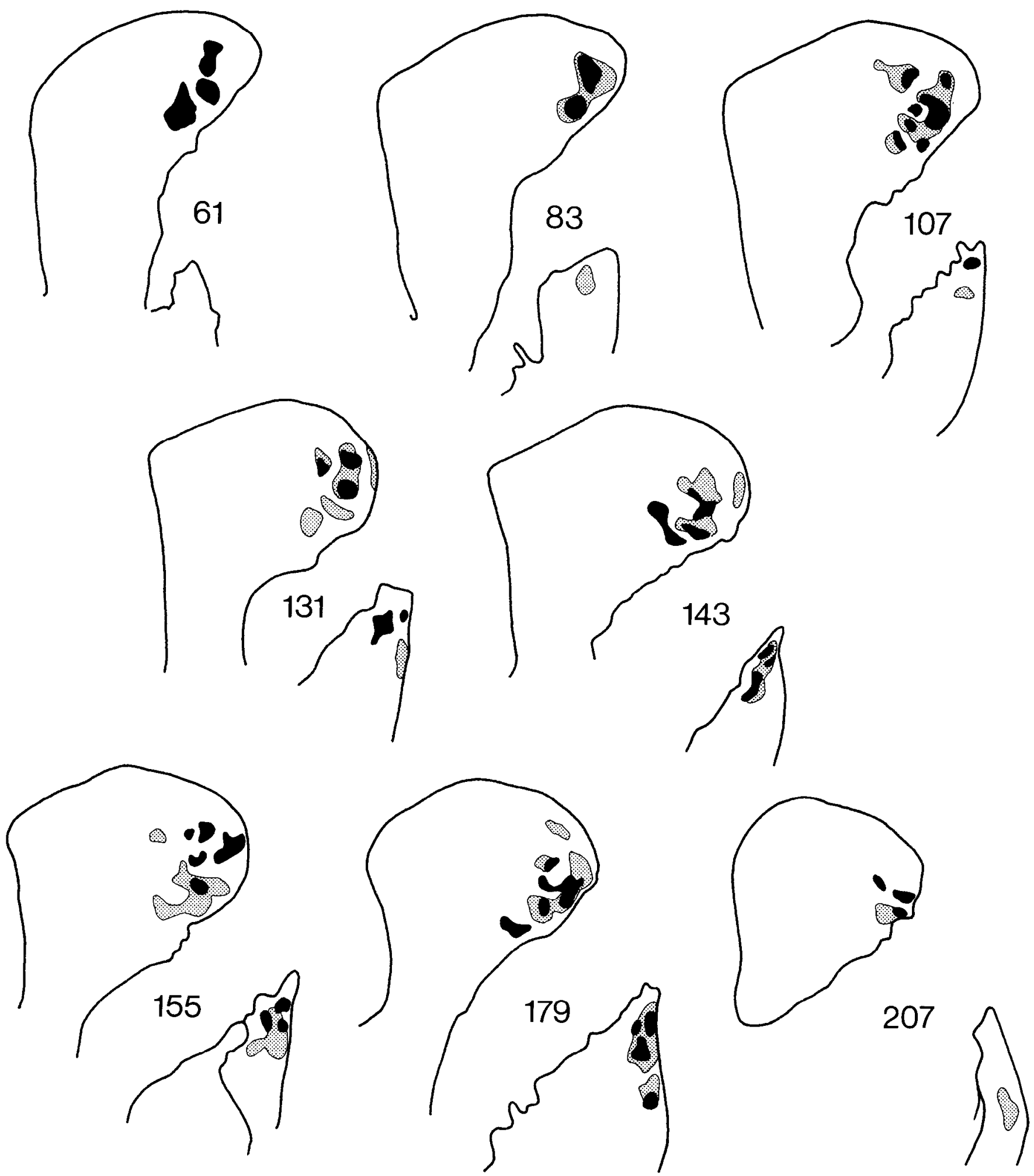

Figure 11. SI recipient zone in the striatum. Drawing tube charts from case CS-21, in which an attempt was made to infiltrate the entire SI region with WGA-HRP and ${ }^{35}$ S-methionine (injection sites shown in Fig. 1). The charts are of the ${ }^{35}$ S-methionine labeling; the WGA-HRP labeling was similar. Numbers indicate section numbers, with 0 the anterior pole of the caudate nucleus. Solid areas indicate dense labeling; stippled zones, fainter labeling. Same conventions as in Figure 5.

guishable tracers. Multiple small, closely spaced injections of WGA-HRP and ${ }^{35}$ S-methionine were placed in areas $3 a$ and SI, respectively. As was true for the case with single injections in the forearm representations of these cortical areas, the striatal regions most intensely labeled by the 2 corticostriatal projections tended to be intermingled, and, at first glance, the 2 projection fields appeared very similar (Fig. 9). There was again a predominant pattern of interdigitation, but with the most dense- 

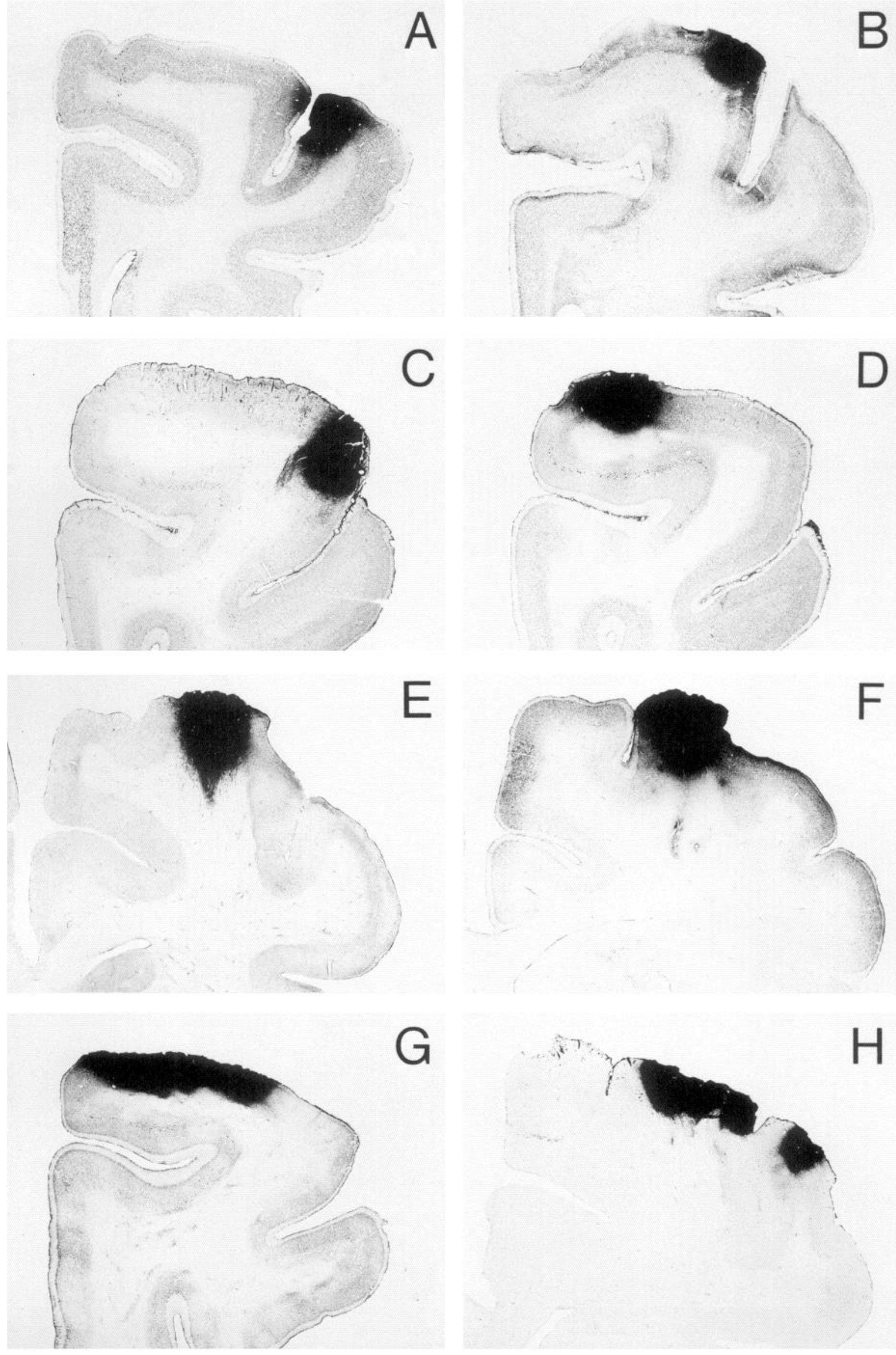
ly labeled cores offset relative to one another within the labeled zone of the striatum. This is illustrated photographically in Figure 9 and in charts in Figure $10 B$.

Although we found clear instances of interdigitation of the densest projection zones labeled from areas $3 \mathrm{a}$ and SI, the correlation of this pattern of projection with somatotopically matched injections of the deep and cutaneous fields was not absolute in the case material studied. Of 4 cats in which our tracer injections appeared reasonably well confined to the deepreceptor and cutaneous representations, 3 shared a predominant pattern of interdigitation of the SI and area $3 a$ corticostriatal projections. In a fourth cat (CS-17), the pattern of striatal labeling following 3 closely spaced injections in area 3 a was quite diffuse and lacked the foci of especially intense labeling typical of the other cases. There was a complex spatial relationship between the "cutaneous" patches and the poorly defined "deep" patches, with a variable degree of alignment between them. The injection sites in area $3 a$ involved rostral parts of the deepreceptor map, but it is unclear whether this accounted for the labeling pattern. The corticostriatal projection labeled from this injection was ipsilateral, as were those traced in the brains in which interdigitation was found.

In 2 additional cases, the tracer deposits in area 3 a spread rostrally into area 4 . The corticostriatal projections labeled by these injections were bilateral and more diffuse than those illustrated in Figures 8 and 9. Finally, in 1 cat (CS-19) we directly compared the projections from the physiologically identified vibrissae-lip representation of area SI with the corticostriatal projection from the roughly somatotopically matched part of somatic sensory area SIII (area 5), which is located caudal and lateral to area SI (Darian-Smith et al., 1966; Dykes et al., 1977; Marshall et al., 1941; Tanji et al., 1978). Like the SI corticostriatal projection, the SIII projection was confined to the dorsolateral region of the striatum and avoided the SP-positive striosomes there. The projection field appeared to be widespread compared with that of SI, however, and the SI patches appeared to be embedded within larger, more diffuse SIII patches.

\section{Borders of the primary somatic sensory projection zone in the striatum}

In every case of area SI injection analyzed, the somatic sensory projections labcled were distributed within a relatively small dorsal and lateral region of the striatum. Establishing the boundaries of this region could clearly be quite useful for future electrophysiological and lesion studies of the striatum. We therefore tried to mark the entire somatic sensory projection from area SI in a single hemisphere (Fig. 11).

The injection site in this cat is shown in Figure 1. Multiple deposits were made throughout the cutaneous representation. Both WGA-HRP (at 16 sites about $1 \mathrm{~mm}$ apart, $15-30 \mathrm{nl}$ at each) and ${ }^{35} \mathrm{~S}$-methionine (at 15 sites, about $1 \mathrm{~mm}$ apart, $60 \mathrm{nl}$ at each) were injected. The resulting HRP injection sites appeared smaller by about a third than the ${ }^{35} \mathrm{~S}$-methionine injection sites. The patterns of striatal labeling, however, were essentially similar for both tracers except that the HRP labeling was somewhat more diffuse. The somatosensory input was strictly ipsilateral and, as true for the cases with smaller injection sites, was broken up into zones that appeared as patches in individual cross sections. Rostrally, the patches were mostly within an arcshaped lateral region of the caudate nucleus, roughly paralleling its lateral border and within the dorsal tip of the putamen. At the caudal end of the zone of innervation, the labeled patches were located within a small dorsal corner of the caudate nucleus and appeared throughout the putamen. The densest and most extensive labeling was around transverse level AP-16-17 of Reinoso-Suarez (1961). Anteroposteriorly, the SI projection zone had a spindle shape, tapering rapidly on both ends. It spanned roughly the central two thirds of the striatum.

\section{Discussion}

The findings of this study relate to 2 levels of striatal organization. With respect to the subdivision of the striatum into relatively large districts, our observations suggest that the region innervated by the primary somatic sensory cortex forms a distinct, internally ordered striatal subdivision much as an individual cortical area represents a regional unit within the cerebral cortex. This ordering strongly supports the notion of regional specialization of the striatum based on its cortical input (Divac et al., 1967; Dunnett and Iversen, 1982; Rosvold and Szwarcbart, 1964) and, in turn, the concept that different striatal sectors may perform different tasks. At the level of the compartmental organization of the striatum, the observations document a subdivision of the extrastriosomal matrix into units that bear a striking resemblance to the histochemically identified striosomes. This heterogeneity suggests that local compartmentalization is a general characteristic of striatal organization, not a special feature pertaining to the striosomal system alone.

\section{Regional subdivisions: the primary somatic sensory sector}

The somatic sensory sector of the striatum was defined here on the basis of the corticostriatal projections of area SI, much as cortical areas can be defined on the basis of the thalamic inputs they receive. This "primary somatic sensory sector" clearly receives other cortical inputs in addition to those from SI. These include corticostriatal projections from somatic sensory areas $3 \mathrm{a}$ and SIII, directly demonstrated in the present experiments; projections to the striosomes in this sector (probably including prefrontal inputs; see Ragsdale and Graybiel, 1981, 1984); and, judging from the cases with injcctions sprcading from area $3 a$ into the motor cortex described above (as well as from unpublished observations of Ragsdale and Graybiel), possibly from area 4 as well. This primary somatic sensory sector is somewhat more elongated rostrocaudally than mediolaterally, but, as delineated even by extensive injections into SI, it did not extend the full length of the striatum, nor did it constitute a narrow tubular domain. It is not certain that all somatic sensory areas of the cortex project to this SI-recipient sector. For example, Burton and Kopf (1984) have described a sparse projection from somatic sensory area SIV to a more ventral striatal region.

The arrangement of the corticostriatal projection of area SI suggests that a composite somatotopic order is maintained in the somatic sensory sector and that the global orientation of the body map there is similar to that in the SI cortex, where rostral body parts are represented lateral to caudal body parts. A similar

\footnotetext{
Figure 12. Examples of injection sites from 5 cases, photographed at the level of the most intense labeling. $A$, ${ }^{35} \mathrm{~S}$-methionine injection into the SI cutaneous vibrissae-lip representation of case CS-19.B, ${ }^{35} \mathrm{~S}-$ methionine injection into the SI cutaneous forepaw representation of the left hemisphere of case CS-20 (reversed for ease of comparison with other panels). C, WGA-HRP injection into the SI cutaneous forepaw digit 4 of case CS-10. $D,{ }^{35}$ S-methionine injection into the SI cutaneous hindpaw representation of case CS-10 (injection site reconstructions of $C$ and $D$ are shown in Fig. $5 A$ ). $E$, WGA-HRP injection into the area 3a deep-receptor forearm representation of case CS-5. $F,{ }^{35} S-$-methionine injection into the SI cutaneous forearm representation of case CS-5 (injection site reconstructions for $E$ and $F$ are shown in Fig. $7 A$ ). $G$, Multiple ${ }^{35} S-$ methionine injections into the area 3a deep-receptor representation of case CS-14. $H$, Multiple WGA-HRP injections into the SI cutaneous representation of case CS-14 (injection site reconstructions of $G$ and $H$ are shown in Fig. $7 \mathrm{C}$ ).
} 
general somatotopy has been described for the corticostriatal projection zone of SI in the macaque monkey (Crutcher and DeLong, 1983; Jones et al., 1977; Künzle, 1975, 1977), although there appears to be greater ventralward rotation of both cortical and striatal maps in the primate compared with their positions in the cat. A more widespread somatic sensory responsiveness has been reported on the basis of recordings made in the caudate putamen of the awake restrained cat (Schneider and Lidsky, 1981). We were unable to determine how the mediolateral body axis is represented in the somatic sensory sector. In the cortex, this axis extends across the narrow anteroposterior dimension of SI, and our injections were too large to differentiate order along this dimension. Without clarifying how this axis is represented in the striatal map, we cannot adequately address the interesting problem of what is represented along the third (roughly anteroposterior) dimension in the striatum.

It is of considerable interest that the primary somatic sensory sector, as defined in our experiments, corresponds to a striatal region that also has histochemical characteristics distinct from those of other striatal districts. In the cat, both the dorsolateral part of the caudate nucleus and the putamen are usually distinguished by a greater diffuseness and greater overall density of AChE staining than are more medial and ventral parts of the striatum. In fact, with AChE histochemistry, striosomes are often difficult to detect in this region or are only hinted at by rims of slightly darker AChE staining, even though they can be demonstrated by other histochemical procedures, including immunohistochemical staining for SP-like immunoreactivity. Occasionally, AChE-rich zones are visible as well (Graybiel and Ragsdale, 1978b, 1983; Sandell et al., 1986). A comparably diffuse and blotchy pattern of AChE staining characterizes the somatic sensory (mainly putamenal) region of the striatum in the macaque monkey (cf. Jones et al., 1977, and Künzle, 1975, with Graybiel and Ragsdale, 1978b). Although the functional significance of this distinctive staining is not clear, it does raise the possibility that the neurotransmitter-related chemistry of the somatic sensory sector may be different from that in other parts of the striatum.

\section{Relationship between the clusters of somatic sensory afferents} and the striosomes in the somatic sensory sector

The findings were unambiguous in demonstrating that the projections from somatic sensory areas SI and 3a, though patchy, avoid the histochemically defined (SP-positive) striosomes. This adds the primary somatic sensory projection to a growing list of striatal afferent systems that obey striosomal ordering by either avoiding striosomes or innervating them. The avoidance pattern is also in line with the report that corticostriatal projections traced from the somatic sensory field in the rat terminate outside the striatal opioid receptor patches (Donoghue and Herkenham, 1983).

The strict avoidance of striosomes by the somatic sensory projection suggests that the main influence of this corticostriatal input is on neurons of the matrix. In separate retrograde tracer experiments in the cat, ncurons in the cxtrastriosomal matrix of the somatic sensory sector have been intensely labeled by tracer deposits centered in the internal pallidum (Graybiel et al., 1979) and the pars reticulata of the substantia nigra (Jimenez-Castellanos and Graybiel, 1985; cf. Gerfen, 1984, 1985, for the rat). These findings make it likely that both striatopallidal and striatonigral connections are influenced by the afferents from the primary somatic sensory cortex, at least in the cat. It is less clear whether there is a smearing of the afferent segregation at the borders between striosomes and matrix by virtue of a spread of dendrites from one tissue compartment to the other. The dendritic processes of certain striatal medium spiny neurons (Bolam et al., 1985; Penny et al., 1984) and also some soma- tostatin-containing medium aspiny neurons (Gerfen, 1984, 1985; Chessclet and Graybicl, 1986) tend to remain within the same type of striatal region-striosomal or extrastriosomal-as their cell bodies of origin. Crossing over of dendrites between striosomes and matrix regions does occur, however (Bolam et al., 1985; Chesselet and Graybiel, 1986; Sandell et al., 1986), so that segregation is incomplete. Almost nothing is yct known about whether the axons of striosomal and matrix neurons are confined to their respective tissue types.

Given these uncertainties, it is not clear whether the intrusion of the striosomes into the somatic sensory sector reflects any definite functional order. In fact, the striosomes and matrix may be largely independent by virtue of the different times of origin and migration of neurons forming the striosomes and matrix (Graybiel, 1984a; Graybiel and Hickey, 1982; Graybiel and Newman-Gage, 1985). If so, their distribution at maturity may be the outcome of a convolving of the 2 tissue types during development. This would suggest that the somatotopic map in the somatic sensory sector jumps over rather than extends across striosomes there. If functional interactions do take place across striosomal borders, at least 2 major possibilities are at issue. The striosomes could actually belong to the same composite map as established by the somesthetic afferents. That is, they could follow a "striosomal somatotopy" in which lateral striosomes perform computations relevant to rostral body part representations, while striosomes placed in the medial part of the somatic sensory sector deal with caudal body part representations. It would be of great interest to learn whether inputs to the striosomes (for example, from frontal cortex) are mapped as well and whether the striosomes that appear in the somatic sensory sector bear any constant relation to particular parts of the body map. Alternatively, the striosomes might have a more uniform, global, and perhaps modulatory effect on the matrix and be distributed in patches so as to provide optimal coverage of the matrix rather than having specialized, local map-specific coverage.

\section{Compartmentalization of the striatal matrix}

Given that the primary somatic sensory cortex projects to the extrastriosomal matrix, the findings reported here provide new information about the organization of this matrix. Despite the near uniformity of the striatal matrix suggested by its histochemical staining properties, our results suggest that the matrix can be broken into separate sets of compartments that resemble striosomes in their cross-sectional sizes and shapes but that lie outside the striosomal labyrinths and as yet lack defining histochemical markers. Several previous studies have demonstrated patchiness and local interdigitation of cortical efferents traced to the striatum (Jones et al., 1977; Künzle, 1975; Liles and Updyke, 1985; Ragsdale and Graybiel, 1981, 1984; Reale and Imig, 1983; Yeterian and Van Hoesen, 1978). In particular, Selemon and Goldman-Rakic (1985), with a double-label anterograde tracer approach similar to that followed here, demonstrated interdigitation of the terminal fields of corticostriatal afferents from widespread areas of neocortex. However, as the striosomal system was not marked out in addition to the afferent-fiber patches, it is unclear whether the interleaving simply reflected the well-known interdigitation of afferents to striosomes and afferents to the matrix. The surprising outcome of the present study is that it provides an unequivocal demonstration of interdigitating fiber systems projecting outside the striosomal system. In fact, for the somatic sensory sector, our findings suggest the presence of multiple sets of local compartments organized within the context of a local somatic sensory map, including (1) striosomes, (2) patches labelcd from arca SI, (3) patches labeled from area $3 a$, and (4) patches intercalated with the others but unlabeled or sparsely labeled and not bearing 


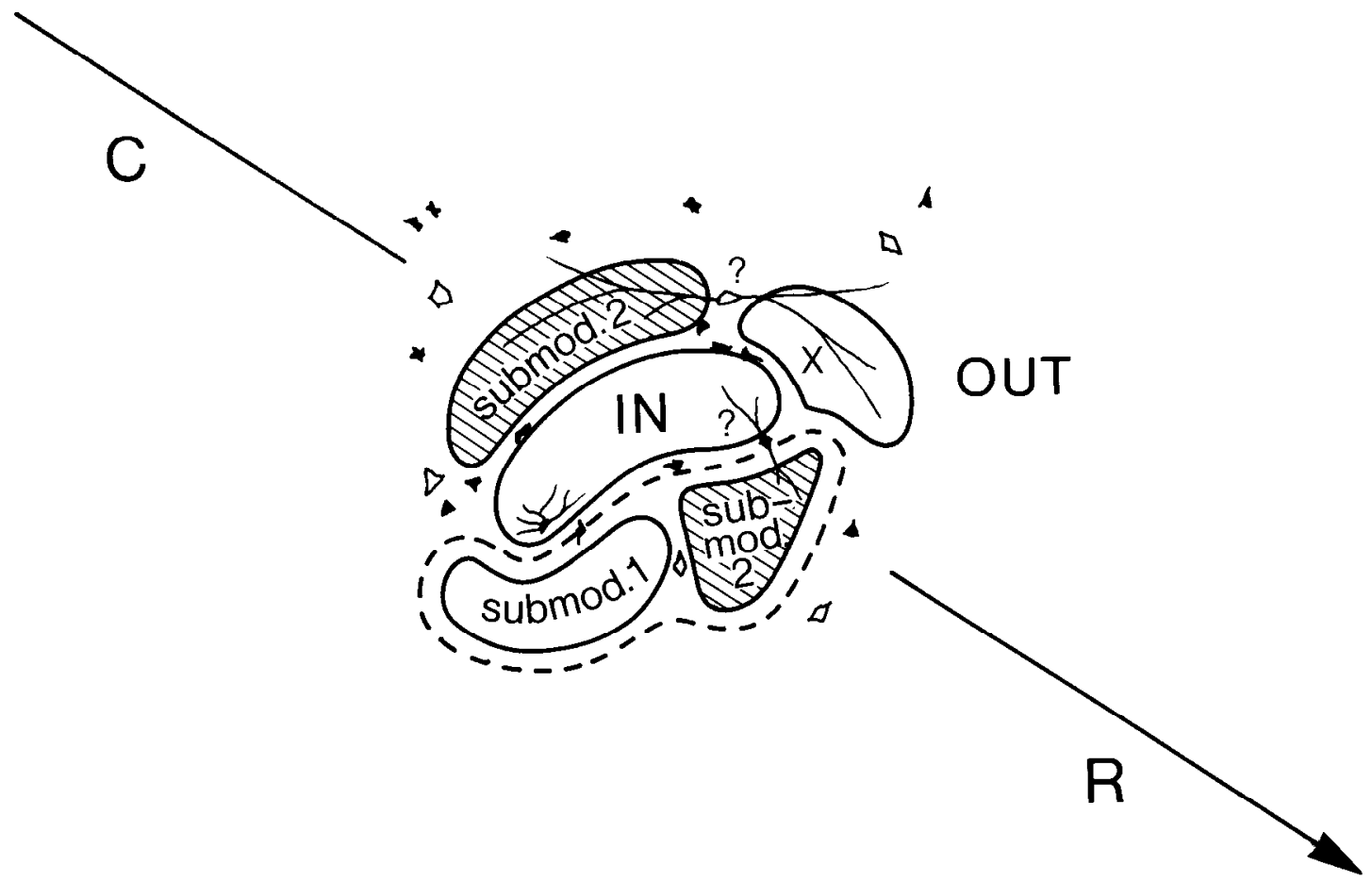

Figure 13. Hypothetical scheme of striatal organization suggested by our results for the somatic sensory sector. The long arrow indicates the overall orderly somatotopy, with more rostral body representations projecting to more lateral striatal regions $(R$, rostral; $C$, caudal). Within this global orderly map there are local interdigitations, first, between striosomes $(I N)$ and matrix $(O U T)$, and second, within the matrix itself, between similar but functionally distinct inputs such as deep-receptor and cutaneous inputs (submod. 1 and submod. 2). Additional input zones (perhaps including nonsomatosensory inputs) are depicted by the patch marked $X$. The interrupted line illustrates the locus of diverging inputs that could innervate more than 1 set of patches. Although this schema is drawn for the somatic sensory sector, a comparable mosaicism within other parts of the striatum is proposed.

the histochemical signature of striosomes.

This heterogeneity of organization of the striatal matrix immediately raises questions about how such extrastriosomal compartments are put together to build up the complete matrix and about the possible functional and developmental significance these compartments might have. Two general types of organization were apparent in the distribution of the somatic sensory afferent-fiber clusters within individual cross sections. By far the most common pattern of innervation seen with paired injections into different parts of the cutaneous SI map was an orderly displacement of 1 set of patches with respect to the second set, the size of their separation being related to the distance between the body part representations. By contrast, the pattern of complex local interdigitation of patches within partially overlapping fields of weaker labeling was seen most clearly in cases in which somatotopically matched deep receptor and cutaneous map injections were paired. These observations suggest that the interdigitating inputs represent the deep and cutaneous inputs to the somatic sensory sector, but the findings do not rule out other alternatives, such as interdigitation between projections from neighboring functional representations (e.g., fast and slowly adapting submodalities) within the cutaneous map (Sretavan and Dykes, 1983). The fact that paired deep/cutaneous injections did not produce interdigitation in every case also suggests that there may be a more complex relation of the corticostriatal projections than simply an interleaving of afferents related to cutaneous and deep submodalities.

Both the systematic shifting of sets of patches and the patterns of interdigitation suggested the presence of a locally detailed somatotopy in the striatal matrix. For technical reasons, however, we could not specify the minimum size of the cortical region that would project to 1 "patch" in the striatum (i.e., that would correspond to a 3-dimensional unit of which 1 patch would be the cross section). Thus, it remains an open question as to whether the borders of the somatic sensory patches delineate true functional units (e.g., separate digit representations) or are formed by a developmental process that breaks up the somatic sensory afferents into separate patches at arbitrary points.

Perhaps the most surprising aspect of the mosaic arrangement of the SI projection to the matrix is that the labeled zones in the extrastriosomal matrix resembled the histochemically defined striosomes so closely in cross-sectional size and shape. It is as though the striosomal labyrinths reflected a general form of organization of the striatum that is covert in the matrix but detectable with many markers in the striosomal labyrinths. Other hints of complexity in the matrix have been noted (Graybiel, 1984a; Nastuk and Graybiel, 1985; Ragsdale and Graybiel, 1981, 1984), but none of these indications of heterogeneity of the matrix have constituted definite demonstrations of compartmental organization, and all have proved difficult to analyze as a result. By contrast, the striosomes originally defined by their low AChE staining can be readily and often sharply delineated by selective arrangements of most striatal connections and neurotransmitter systems and by the specialized ontogeny of striosomal neurons as defined by their birthdates. Whether the compartmental units of the matrix have a comparable individuality that simply has not yet been detected or lack such singular histochemical and other characteristics is not known. Worth noting, however, is Brand and Rakic's report (1979) that ${ }^{3} \mathrm{H}$ thymidine-labeled neurons in the striatum are distributed in patches following initial exposure to the thymidine at gestational ages spanning most of the time of neurogenesis of the striatum. These observations are compatible with a compartmentalized origin of matrix neurons, and this possibility is certainly not 
excluded by the finding that there is a particular time window in which neurons of the striosomes undergo their last or nearfinal division (Graybiel and Hickey, 1982).

\section{Mosaic organization of the striatum: generalization of the striosome concept}

A general plan of organization for the somatic sensory sector of the striatum is indicated by the findings described here. First, the region appears to contain a global map of the body based on somatic sensory coordinates derived from the cortex. Second, within this map, distinguishable subclasses of somatic sensory input appear to interdigitate with one another. Third, the entire map appears to interdigitate with the striosomal system present in that region. Finally, other patchworks appear to exist in the matrix, for even with injections infiltrating large parts of both the $3 \mathrm{a}$ and SI cortex, there were zones within the somatic sensory sector that seemed to be avoided both by the labeled corticostriatal afferents and by the SP-positive striosomes. The region as a whole thus truly appears to have the form of a mosaic, at least as judged by the distributions of afferent-fiber patches, spared patches, and striosomes in individual cross sections. This notion is schematically depicted in Figure 13.

It is by now apparent that modular organization is a general characteristic of the CNS but that the modularity takes different forms in different regions. In this regard, there is an interesting similarity between the particular arrangement of the striatum proposed here and the organization that is now being uncovered in the intermediate gray layer of the superior colliculus. There, as in the striatum, a set of histochemically distinct patches can be identified in cross sections stained for AChE and neuropeptide-like immunoreactivity (Graybiel et al., 1984; Illing and Graybiel, 1985). The collicular patches have been shown to correspond to parts of 3-dimensional arrays in which certain afferent fiber systems, but not others, terminate. As we show here for the striatum, there are other afferent-fiber patchworks terminating in the vicinity of, but at sites separate from, these histochemically defined collicular patches (Illing and Graybiel, 1986). Both in the superior colliculus and in the striatum, in other words, sets of histochemically defined patches may serve a special purpose by virtue of their biochemical specialization but may at the same time reflect a general compartmental organization of the tissue. The cytochrome oxidase-rich "blobs" in the upper layers of the primate visual cortex represent another example of local histochemical compartmentalization within a broader field (Hendrickson et al., 1981; Livingstone and Hubel, 1984; Wong-Riley, 1979), but whether there is comparable compartmentalization of the "nonblob" regions of these layers is not clear.

The scheme of striatal matrix organization suggested by our findings raises the possibility that local interactions could occur between the submodality-specific somatic sensory patches much as interdigitation between representations of the 2 eyes in the striate cortex is thought to facilitate local computations required for stereopsis (Wiesel et al., 1974). From the variety of cutaneous and deep receptor afferent stimulation activating areas SI and $3 \mathrm{a}$-including the dense representation of muscle spindle afferents in area 3a (Jones and Porter, 1980; Silfvenius, 1970)-one could guess that the corticostriatal somatic sensory patchworks provide an essential component of motor tasks involving ongoing monitoring of tactile and kinesthetic cues. What exactly their function is, however, and whether they might be involved in purcly scnsory tasks as well, is still completely unknown. More generally, these observations on the somatic sensory sector raise the possibility that a form of mosaic organization holds also for the extrastriosomal matrix in other parts of the striatum. Given the evidence for heterogeneity in the terminal patterns of nearly all striatal afferents (Beckstead, 1985; Goldman and Nauta, 1977; Graybiel, 1982; Herkenham and Pert, 1981; Ji-
menez-Castellanos and Graybiel, 1985; Jones et al., 1977; Kalil, 1978; Kelley et al., 1982; Künzle, 1975, 1977, 1978; Künzle and Akert, 1977; Ragsdale and Graybiel, 1981, 1984; Reale and Imig, 1983; Royce, 1978; Russchen et al., 1985; Selemon and Goldman-Rakic, 1985; Steinbusch, 1981; Van Hoesen et al., 1981; Wright and Arbuthnott, 1981; Yeterian and Van Hoesen, 1978 ), this seems a reasonable prediction. Such a mosaic, if present, could determine the types of interactions occurring not only between striosomes and the extrastriosomal matrix, but also between different classes of afferents innervating the matrix.

\section{References}

Alexander, G. E. (1984) Instruction-dependent neuronal activity in primate putamen. Soc. Neurosci. Abstr. 10: 515.

Beckstead, R. M. (1985) Complementary mosaic distributions of thalamic and nigral axons in the caudate nucleus of the cat: double anterograde labeling combining autoradiography and wheat germHRP histochemistry. Brain Res. 335: 153-159.

Beckstead, R. M., and K. S. Kersey (1985) Immunohistochemical demonstration of differential substance $\mathbf{P}$-, met-enkephalin-, and glutamic acid decarboxylase-containing cell body and axon distributions in the corpus striatum of the cat. J. Comp. Neurol. 232: 481-498.

Bolam, J. P., P. N. Izzo, and A. M. Graybiel (1985) Golgi-impregnation of the cat neostriatum combined with immunocytochemistry for substance P or met-enkephalin. Neurosci. Lett. [Suppl.] 22: 281.

Brand, S., and P. Rakic (1979) Genesis of the primate neostriatum: $\left[{ }^{3} \mathrm{H}\right]$ thymidine autoradiographic analysis of the time of neuron origin in the rhesus monkey. Neuroscience 4: 767-778.

Burton, H., and E. M. Kopf (1984) Ipsilateral cortical connections from the second and fourth somatic sensory areas in the cat. J. Comp. Neurol. 225: 527-553.

Chesselet, M.-F., and A. M. Graybiel (1986) Striatal neurons expressing somatostatin-like immunoreactivity: Evidence for a peptidergic interneuronal system in the cat. Neuroscience (in press).

Cowan, W. M., D. E. Gottlieb, A. E. Hendrickson, J. L. Price, and T. A. Woolsey (1972) The autoradiographic demonstration of axonal connections in the central nervous system. Brain Res. 37: 21-51.

Crutcher, M. D., and M. R. DeLong (1983) Single cell studies of the primate putamen. 1. Functional organization. Exp. Brain Res. 130 . $1-11$.

Darian-Smith, I., J. Isbistcr, H. Mok, and T. Yokota (1966) Somatic sensory cortical projection areas excited by tactile stimulation of the cat: A triple representation. J. Physiol. (Lond.) 182: 671-689.

DiFiglia, M., T. Pasik, and P. Pasik (1978) A Golgi study of afferent fibers in the neostriatum of monkeys. Brain Res. 152: 341-347.

Divac, I. (1983) Two levels of functional heterogeneity of the neostriatum. Neuroscience 10:1151-1155.

Divac, I., H. E. Rosvold, and M. K. Szwarcbart (1967) Behavioural effects of selective ablation of the caudate nucleus. J. Comp. Physiol. Psychol. 63: 184-190.

Donoghue, J. P., and M. Herkenham (1983) Multiple patterns of corticostriatal projections and their relationship to opiate receptor patches in rats. Soc. Neurosci. Abstr. 9: 15.

Dunnett, S. B., and S. D. Iversen (1982) Sensorimotor impairments following localised kainic acid and 6-hydroxydopaminc lcsions of the neostriatum. Brain Res. 248: 121-127.

Dykes, R. W., J. D. Dudar, D. G. Tanji, and N. G. Publicover (1977) Somatotopic projection of mystacial vibrissae on cerebral cortex of cats. J. Neurophysiol. 40: 997-1014.

Dykes, R. W., D. D. Rasmusson, and P. B. Hoeltzell (1980) Organization of primary somatosensory cortex in the cat. J. Neurophysiol 43: $1527-1546$

Felleman, D. J., J. T. Wall, C. G. Cusick, and J. H. Kaas (1983) The representation of the body surface in SI of cats. J. Neurosci. 3: 16481669.

Fishell, G., and D. van der Kooy (1984) Caudate efferents in perinatal rats originate primarily from patches receiving dopaminergic input. Soc. Neurosci. Abstr. 10: 704.

Geneser-Jensen, F. A., and J. W. Blackstad (1971) Distribution of acetylcholinesterase in the hippocampal region of the guinea pig. I. Entorhinal area, parasubiculum, and presubiculum. Z. Zellforsch. Mikrosk. Anat. 114: 460-481.

Gerfen, C. R. (1984) The neostriatal mosaic: Compartmentalization 
of corticostriatal input and striatonigral output systems. Nature 311 : $461-464$.

Gerfen, C. R. (1985) The neostriatal mosaic. I. Compartmental organization of projections from the striatum to the substantia nigra in the rat. J. Comp. Neurol. 236: 454-476.

Gerfen, C. R., and P. E. Sawchenko (1984) An anterograde neuroanatomical tracing method that shows the detail morphology of neurons, their axons and terminals: Immunohistochemical localization of an axonally transported plant lectin, Phaseolous vulgaris leucoagglutinin (PHA-L). Brain Res. 290: 219-238.

Goedert, M., P. W. Mantyh, P. C. Emson, and S. P. Hunt (1984) Inverse relationship between neurotensin receptors and neurotensinlike immunoreactivity in cat striatum. Nature 307: 543-546.

Goldman, P. S., and W. J. H. Nauta (1977) An intricately patterned prefronto-caudate projection in the rhesus monkey. J. Comp. Neurol. 171: 369-386.

Graybiel, A. M. (1982) Correlative studies of histochemistry and fiber connections in the central nervous system. In Cytochemical Methods in Neuroanatomy, V. Chan-Palay and S. Palay, eds., pp. 46-67, Liss, New York.

Graybiel, A. M. (1984a) Correspondence between the dopamine islands and striosomes of the mammalian striatum. Neuroscience 13: 1157-1187.

Graybiel, A. M. (1984b) Neurochemically specified subsystems in the basal ganglia. In Functions of the Basal Ganglia (Ciba Foundation Symposium 107), D. Evered and M. O'Connor, eds., pp. 114-149, Pitman, London.

Graybiel, A. M., and M.-F. Chesselet (1984) Compartmental distribution of striatal cell bodies expressing met-enkephalin-like immunorcactivity. Proc. Natl. Acad. Sci. USA 81: 7980-7984.

Graybiel, A. M., and M. Devor (1974) A microelectrophoretic delivery technique for use with horseradish peroxidase. Brain Res. 68: 167173.

Graybiel, A. M., and T. L. Hickey (1982) Chemospecificity of ontogenetic units in the striatum demonstrated by combining ${ }^{3} \mathrm{H}$-thymidine neuronography and histochemical staining. Proc. Natl. Acad. Sci. USA 79: 198-202.

Graybiel, A. M., and Newman-Gage, H. (1985) The developmental relationship between dopamine islands and early striosomal neuron clusters in the fetal cat striatum. Soc. Neurosci. Abstr. 11: 205.

Graybiel, A. M., and C. W. Ragsdale, Jr. (1978a) Striosomal organization of the caudate nucleus: I. Acetylcholinesterase histochemistry of the striatum in the cat, rhesus monkey and human being. Soc. Ncurosci. Abstr. 4: 44.

Graybiel, A. M., and C. W. Ragsdale, Jr. (1978b) Histochemically distinct compartments in the striatum of human, monkey and cat demonstrated by acetylthiocholinesterase staining. Proc. Natl. Acad. Sci. USA 75: 5723-5726.

Graybiel, A. M., and C. W. Ragsdale, Jr. (1979) Fiber connections of the basal ganglia. Prog. Brain Res. 51: 239-283.

Graybiel, A. M., and C. W. Ragsdale, Jr. (1983) Biochemical anatomy of the striatum. In Chemical Neuroanatomy, P. C. Emson, ed., pp. 427-504, Raven, New York.

Graybiel, A. M., C. W. Ragsdale, Jr., and S. Moon Edley (1979) Compartments in the striatum of the cat ohserved by retrograde cell labeling. Exp. Brain Res. 34: 189-195.

Graybiel, A. M., C. W. Ragsdale, Jr., E. S. Yoneoka, and R. P. Elde (1981) An immunohistochemical study of enkephalines and other neuropeptides in the striatum of the cat with evidence that the opiate peptides are arranged to form mosaic patterns in register with the striosomal compartments visible by acetylcholinesterase staining. Neuroscience 6: 377-397.

Graybiel, A. M., N. Brecha, and H. J. Karten (1984) Cluster-and-sheet pattern of enkephalin-like immunoreactivity in the superior colliculus of the cat. Neuroscience 12: 191-214.

Hassler, R., and K. Muhs-Clement (1964) Architektonischer Aufbau des sensorimotorischen und parietalen Cortex der Katze. J. Hirnforsch. $6: 377-420$.

Hendrickson, A., L. Moe, and B. Nobel (1972) Staining for autoradiography of the central nervous system. Stain Technol. 47: 283-290.

Hendrickson, A. E., S. P. Hunt, and J.-Y. Wu (1981) Immunocytochemical localization of glutamic acid decarboxylase in monkey striate cortex. Nature 292: 605-607.

Herkenham, M., and C. B. Pert (1981) Mosaic distribution of opiate receptors, parafascicular projections and acetylcholinesterase in rat striatum. Nature 291: 415-418.
Illing, R. B., and A. M. Graybiel (1985) Convergence of afferents from frontal cortex and substantia nigra onto acetylcholinesterase-rich patches of the cat's superior colliculus. Neuroscience 14: 455-482.

Illing, R. B., and A. M. Graybiel (1986) Complementary and nonmatching afferent compartments in the cat's superior colliculus: Innervation of the acetylcholinesterase-poor domain of the intermediate gray layer. Neuroscience 18: 373-394.

Illing, R. B., and $\mathbf{H}$. Wässle (1979) Visualization of the HRP reaction product using the polarization microscope. Neurosci. Lett. 13: 7-11.

Jimenez-Castellanos, J., and A. M. Graybiel (1985) The dopaminecontaining innervation of striosomes: Nigral subsystems and their striatal correspondents. Soc. Neurosci. Abstr. 11: 1249.

Jones, E. G., and R. Porter (1980) What is area 3a? Brain Res. Rev. 2: $1-43$.

Jones, E. G., J. D. Coulter, H. Burton, and R. Porter (1977) Cells of origin and terminal distribution of corticostriatal fibers arising in the sensory-motor cortex of monkeys. J. Comp. Neurol. 173: 53-80.

Kaas, J. H. (1983) What, if anything, is SI?: The organization of the "first somatosensory area" of cortex. Physiol. Rev. 63: 206-230.

Kalil, K. (1978) Patch-like termination of thalamic fibers in the putamen of the rhesus monkey: An autoradiographic study. Brain Res. 140: 333-339.

Kelley, A. E., V. B. Domesick, and W. J. H. Nauta (1982) The amygdalostriatal projection in the rat-an anatomical study by anterograde and retrograde tracing methods. Neuroscience 7: 615-630.

Künzle, H. (1975) Bilateral projections from precentral motor cortex to the putamen and other parts of the hasal ganglia. Brain Res. 88 : 195-210.

Künzle, H. (1977) Projections from the primary somatosensory cortex to basal ganglia and thalamus in the monkey. Exp. Brain Res. 30: 481-492.

Künzle, H. (1978) An autoradiographic analysis of the efferent connections from premotor and adjacent prefrontal regions (areas 6 and 9) in Macaca fascicularis. Brain Behav. Evol. 15: 185-234.

Künzle, H., and K. Akert (1977) Efferent connections of cortical area 8 (frontal eye field) in Macaca fasicularis. A reinvestigation using the autoradiographic method. J. Comp. Neurol. 173: 147-164.

Landgren, S., and H. Silfvenius (1969) Projection to cerebral cortex of group 1 muscle afferents from the cat's hind limb. J. Physiol. (Lond.) 200: 353-372.

Levick, W. R. (1972) Another tungsten microelectrode. Med. Biol. Engin. 10: 510-515.

Liles, S. L., and B. V. Updyke (1985) Projection of the digit and wrist area of precentral gyrus to the putamen: Relation between topography and physiological properties of neurons in the putamen. Brain Res. 339: $245-255$.

Livingstone, M. S., and D. H. Hubel (1984) Anatomy and physiology of a color system in the primate visual cortex. J. Neurosci. 4: 309356.

Malach, R., and A. M. Graybiel (1984) Organization of somatosensory corticostriatal projections. Soc. Neurosci. Abstr. 10: 513.

Marshall, W. H., C. N. Woolsey, and P. Bard (1941) Observations on cortical somatic sensory mechanisms of cat and monkey. J. Neurophysiol. 4: 1-24.

McCulloch, J., K. Kirkham, H. MacPherson, and J. Sharkey (1983) Functional organization of the caudate nucleus defined by serial 2-deoxyglucose autoradiography and histochemistry. J. Cereb. Blood Flow Metab. 3 [Suppl.]: S258-S259.

McKenna, T. M., B. L. Whitsel, D. A. Dreyer, and C. B. Metz (1981) Organization of cat anterior parietal cortex: Relation among cytoarchitecture, single neuron functional properties, and interhemispheric connectivity. J. Neurophysiol. 45: 667-697.

Mesulam, M. M. (1978) Tetramethyl benzidine for horseradish peroxidase neurohistochemistry: A non-carcinogenic blue reaction product with superior sensitivity for visualizing neural afferents and efferents. J. Histochem. Cytochem. 26: 106-117.

Mountcastle, V. B. (1957) Modality and topographic properties of single neurons of cat's somatic sensory cortex. J. Neurophysiol. 20 : 408-434.

Nastuk, M. A., and A. M. Graybiel (1985) Patterns of muscarinic cholinergic binding in the striatum and their relation to dopamine islands and striosomes. J. Comp. Neurol. 237: 176-194.

Olson, L., A. Seiger, and K. Fuxe (1972) Heterogeneity of striatal and limbic dopamine innervation: Highly fluorescent islands in developing and adult rats. Brain Res. 44: 283-288.

Penny, G. R., C. J. Wilson, and S. T. Kitai (1984) The influence of 
neostriatal patch and matrix compartments on the dendritic geometry of spiny projection neurons in the rat as revealed by intracellular labeling with HRP combined with immunocytochemistry. Soc. Neurosci. Abstr. 10: 514.

Pert, C. B., M. J. Kuhar, and S. H. Snyder (1976) Opiate receptors: Autoradiographic localization in rat brain. Proc. Natl. Acad. Sci. USA 73: 3729-3733.

Ragsdale, C. W., and A. M. Graybiel (1981) The fronto-striatal projection in the cat and monkey and its relationship to inhomogeneities established by acetylcholinesterase histochemistry. Brain Res. 208: 259-266.

Ragsdale, C. W., and A. M. Graybiel (1984) Further observations on the striosomal organization of frontostriatal projections in cats and monkeys. Soc. Neurosci. Abstr. 10: 514.

Reale, R. A., and T. J. Imig (1983) Auditory cortical field projections to the basal ganglia of the cat. Neuroscience $8: 67-86$.

Reinoso-Suarez, F. (1961) Topographischer Hirnatlas der Katze für Experimental-physiologische Untersuchungen. E. Merck, Darmstadt, FRG.

Rosvold, H. E., and M. K. Szwarcbart (1964) Neural structures involved in delayed response performance. In The Frontal Granular Cortex and Behavior, J. M. Warren and K. Akert, eds., pp. 1-15, McGraw-Hill, New York.

Royce, G. J. (1978) Autoradiographic evidence for a discontinuous projection to the caudate nucleus from the centromedial nucleus in the cat. Brain Res. 146: 145-150.

Russchen, F. T., I. Bakst, D. G. Amaral, and J. L. Price (1985) The amygdalostriatal projections in the monkey, an anterograde tracing study. Brain Res. 329: 241-257.

Sandell, J. H., A. M. Graybiel, and M.-F. Chesselet (1986) A new enzyme marker for striatal compartmentalization: NADPH diaphorase activity in the caudate nucleus and putamen of the cat. J. Comp. Neurol. 243: 326-334.

Schneider, J. S., and T. I. Lidsky (1981) Processing of somatosensory information in striatum of behaving cats. J. Neurophysiol. 45: 841851.

Selemon, L. D., and P. S. Goldman-Rakic (1985) Longitudinal topography and interdigitation of corticostriatal projections in the rhesus monkey. J. Neurosci. 5: 776-794.
Silfvenius, H. (1970) Projections to the cerebral cortex from afferents of the interosseous nerves of the cat. Acta Physiol. Scand. 80: 196214.

Sims, K. L., F. C. Kauffman, E. C. Johnson, and V. M. Pickel (1974) Cytochemical localization of brain nicotinamide adenine dinucleotide phosphate (oxidized)-dependent dehydrogenases. J. Histochem. Cytochem. 22: 7-19.

Sretavan, D., and R. W. Dykes (1983) The organization of two cutaneous submodalites in the forearm region of area $3 \mathrm{~b}$ of cat somatosensory cortex. J. Comp. Neurol. 213: 381-398.

Steinbusch, H. W. M. (1981) Distribution of serotonin-immunoreactivity in the central nervous system of the rat cell bodies and terminals. Neuroscience 6: 557-618.

Sternberger, L. A. (1979) Immunocytochemistry, Wiley, New York.

Tanji, D. G., S. P. Wise, R. W. Dykes, and E. G. Jones (1978) Cytoarchitecture and thalamic connectivity of third somatosensory area of cat cerebral cortex. J. Neurophysiol. $41: 268-284$.

Tennyson, V. M., R. E. Barrett, G. Cohen, L. Cote, R. Heikkila, and C. Mytilineou (1972) The developing neostriatum of the rabbit: Correlation of fluorescence histochemistry, electron microscopy, endogenous dopamine levels, and ${ }^{3} \mathrm{H}$-dopamine uptake. Brain Res. 46: $251-285$.

Van Hoesen, G. W., E. H. Yeterian, and R. Lavizzo-Mourey (1981) Widespread corticostriate projections from temporal cortex of the rhesus monkey. J. Comp. Neurol. 199: 205-219.

Wiesel, T. N., D. H. Hubel, and D. M. K. Lam (1974) Autoradiographic demonstration of ocular-dominance columns in the monkcy striate cortex by means of transneuronal transport. Brain Res. 79: 273-279.

Wong-Riley, M. T. T. (1979) Changes in the visual system of monocularly sutured or enucleated cats demonstrable with cytochrome oxidase histochemistry. Brain Res. 171: 11-28.

Wright, A. K., and G. W. Arbuthnott (1981) The pattern of innervation of the corpus striatum by the substantia nigra. Neuroscience $6: 2063-$ 2067.

Yeterian, E. H., and G. W. Van Hoesen (1978) Cortico-striate projections in the rhesus monkey: The organization of certain corticocaudate connections. Brain Res. 139: 43-63. 